\title{
SAPONIN REMOVAL FROM QUINOA BY ABRASION PROCESSING
}

\author{
A Thesis \\ presented to \\ the Faculty of California Polytechnic State University, \\ San Luis Obispo \\ In Partial Fulfillment \\ of the Requirements for the Degree \\ Master of Science in Agriculture with a Specialization in Food Science
}

by

Luke Lundberg

June 2019 
(C) 2019

Luke Lundberg

ALL RIGHTS RESERVED 
COMMITTEE MEMBERSHIP

TITLE: $\quad$ Saponin Removal from Quinoa by Abrasion Processing

AUTHOR: Luke Lundberg

DATE SUBMITTED: June 2019

COMMITTEE CHAIR: Gour Choudhury, Ph.D.

Professor of Food Science

COMMITTEE MEMBER: Luis Castro, Ph.D.

Assistant Professor of Food Science

COMMITTEE MEMBER: Michael Heying, Ph.D.

Assistant Professor of Chemical Engineering 


\section{ABSTRACT \\ Saponin Removal from Quinoa by Abrasion Processing \\ Luke Lundberg}

Quinoa is coated with a thin layer of saponins, glycosylated triterpenoids, that produce a bitter flavor when consumed. The average saponin content in commercial varietals from Bolivia average around 2.7\% saponins and organoleptic testing shows the threshold for noticing a bitter flavor is below 0.12\% (Medina-Meza et al., 2016). Current industrial processing methods use a combination of abrasion and turbulent water flow to remove saponin. This study will address the following research question: How will grainto-grain and grain-to-surface abrasion affect the processing time to remove saponin from quinoa? In particular, can effective saponin removal be achieved in less than 10 minutes without washing with water?

Three different laboratory scale systems for generating grain-to-grain abrasion alone and in combination with grain-to-surface abrasion were constructed. Preliminary studies using mass balance and visual observation found the tubular system removed $4.45 \%$ of the quinoa mass in saponin containing fractions compared to the conical system $(1.33 \%)$ and fluidized bed $(0.62 \%)$.

After preliminary studies, a saponin estimation method was adapted and the conditions of the tubular system were determined. A randomized experiment was carried out in triplicate at three levels of time (5, 10, and 15 minutes) and mass (200, 300, and 400 grams). The effect of surface roughness in the tubular system was also evaluated. The samples were collected and saponin content in each sample was quantified using the adapted method. The saponin levels were compared to commercially processed quinoa in the market.

The processing conditions of 15 minutes at an input mass of 300 grams yielded the lowest saponin level of $0.19 \%$. The four processing conditions of ( 10 minutes $/ 200$ grams, 10 minutes/400 grams, 15 minutes/200 grams and 15 minutes/300 grams) were statistically different $(\mathrm{p}<0.05)$ from the control (unprocessed quinoa). The effects of process time, input mass, and the interaction between process time and input mass were not statistically significant. The impact of surface friction on the removal of saponin found no statistical difference ( $\mathrm{p}<0.05)$ between the samples. The quinoa processed by the tubular system (15 minutes and 300 grams) had the lowest saponin level $(0.19 \%)$ compared to four commercially processed quinoa (0.21-0.31\%).

The tubular system showed promise for reducing process time and saponin content in commercially processed quinoa without washing. However, further experimentation is needed for industrial implementation. The system would provide the industry with a sustainable process with better saponin removal capacity.

Keywords: quinoa, saponins, abrasion, grain-to-grain, Saponin Quantification by UVVis Spectrophotometry, tubular system, conical system, fluidized bed system 


\section{ACKNOWLEDGMENTS}

I am very thankful for the privilege of working with my major advisor Dr. Gour S. Choudhury. His support, patience, honest feedback and guidance could not go unnoticed in the completion of this project. I am truly grateful for all he has done.

I would like to thank Lundberg Family Farms for their generous donations and access to production and research staff. This project would have been challenging without their support.

I would like to thank the members of my committee and graduate coordinator for their dedication in seeing the project through to the end and providing meaningful support and direction, Dr. Luis Castro, Dr. Michael Heying, and Dr. Stephanie Jung.

I would like to thank the Department of Food Science and Nutrition and California Polytechnic State University, San Luis Obispo for allowing me to complete this study in their facilities. I would like to acknowledge the financial support received from the department.

Special thanks are due to the following individuals for assisting in the completion of this project, Molly Lear, Dr. Michael La Frano, Erin Foote, Dr. Samir Amin, Fionna Fahey, Heather Smith, and Rob Fanter. 




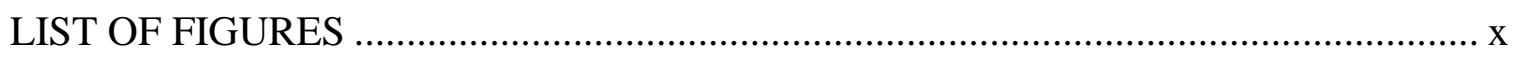

\section{CHAPTERS}



1.1. Statement of Problem .................................................................................... 1

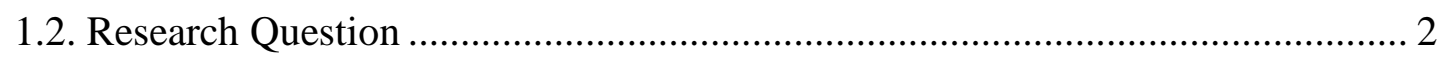

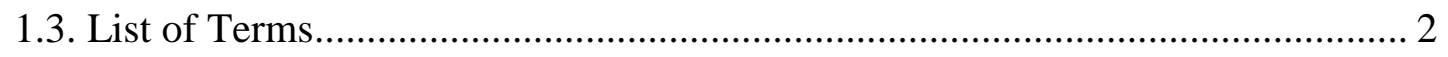

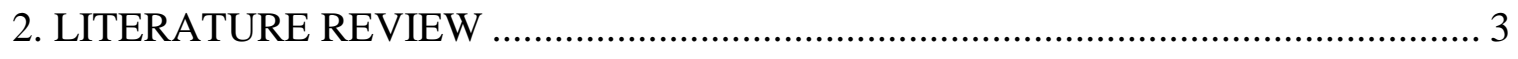

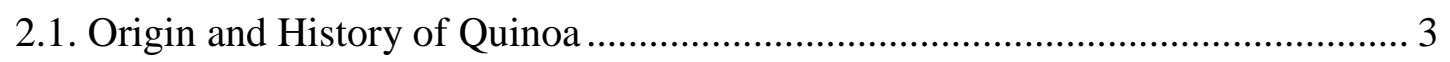

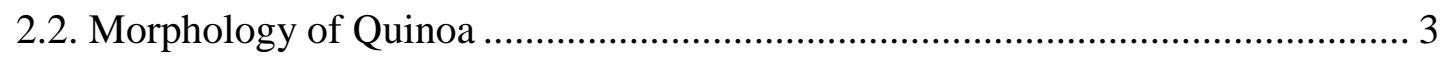

2.3. Climate Conditions for Growing Quinoa ………….......................................... 5

2.4. Composition and Nutrition Value of Quinoa...................................................... 5

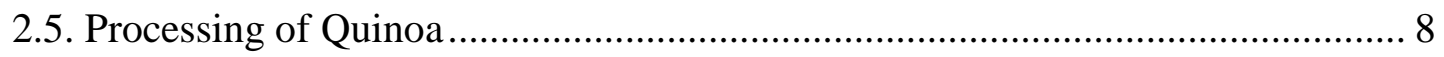

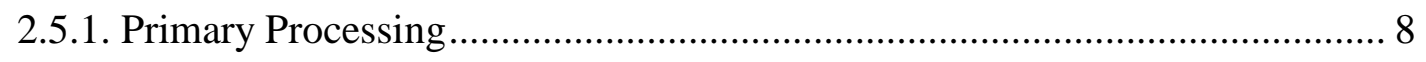

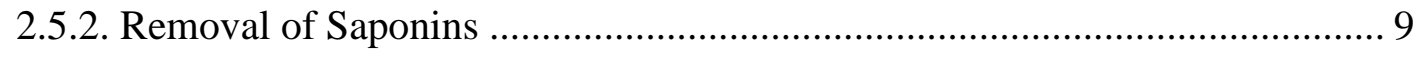

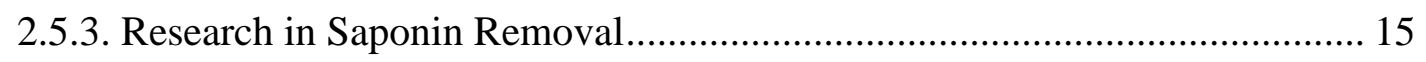



2.6. Consumption of Quinoa............................................................................. 17

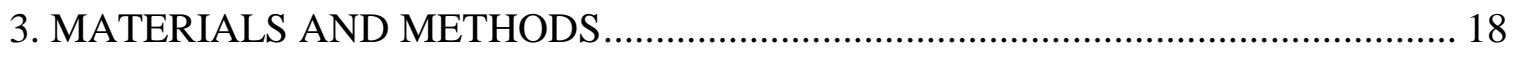

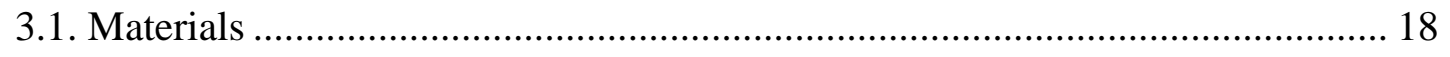




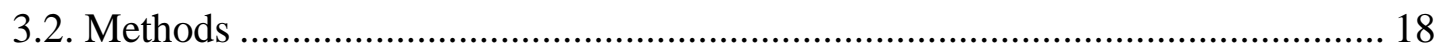

3.2.1. Design and Fabrication of Abrasion Equipment ..................................... 18

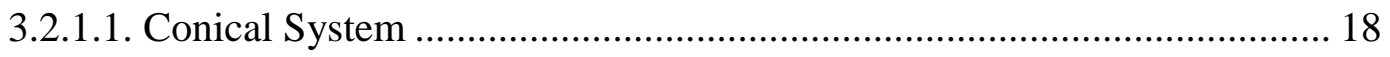

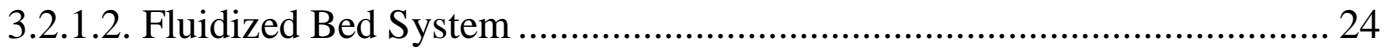

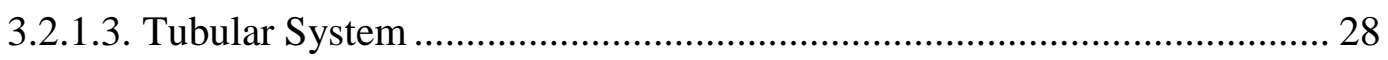



3.2.2.1. Preliminary Experiments with Conical, Fluidized Bed, and Tubular

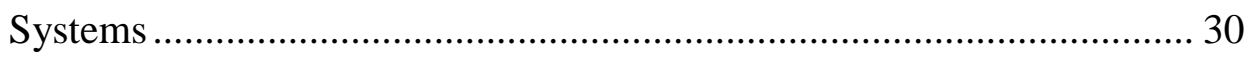



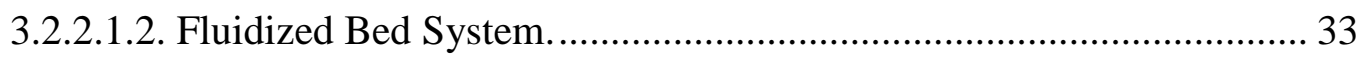

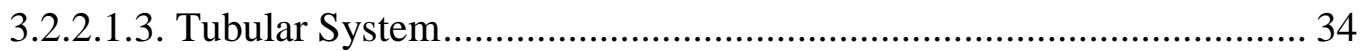

3.2.2.1.4. Evaluation of System Performance ............................................ 35

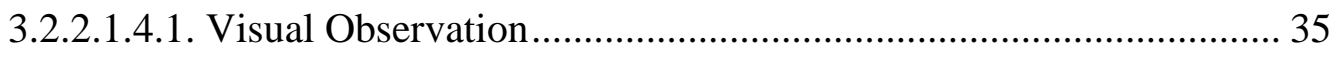

3.2.2.1.4.2. Mass Balance ......................................................................... 36

3.2.2.2. Final Experiment with Tubular System .......................................... 36

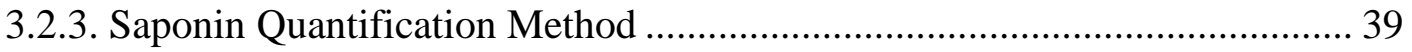

3.2.3.1. Adaptations to the Saponin Quantification Method................................ 39

3.2.3.2. Saponin Quantification using the Adapted Method............................... 40

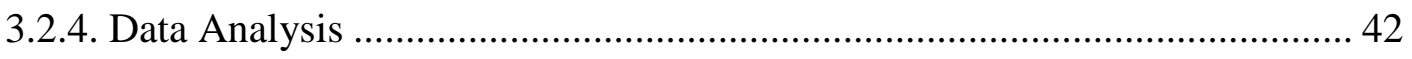



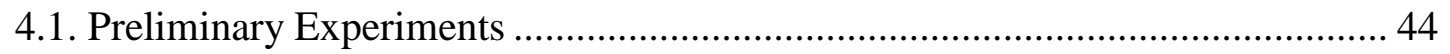

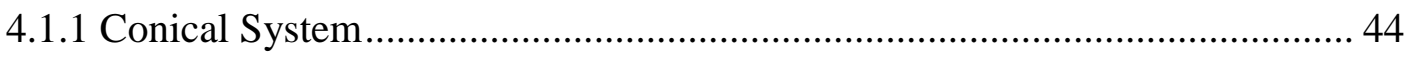

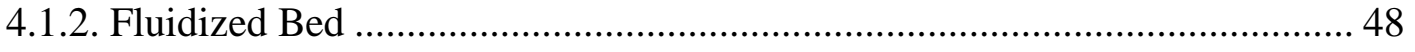

4.2.1. Final Adapted Method for Saponin Quantification .................................... 53 
4.3. Final Experiment with Tubular System ....................................................... 54

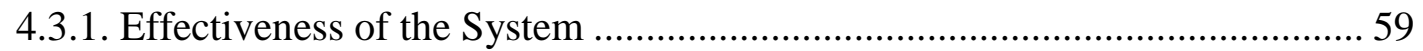



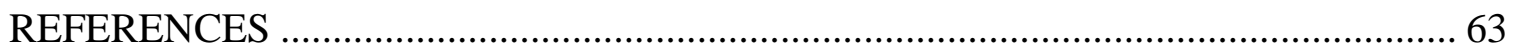




\section{LIST OF TABLES}

Table

Page

2.1 Amino Acid Composition (mg/g Protein) of the Proteins in Quinoa and Other Cereal Grains in Comparison to the WHO/FAO/UNU Scoring Pattern for Young Children (6 Months to 3 Years) and Older Children, Adolescent, and Adult (3-10 Years). .

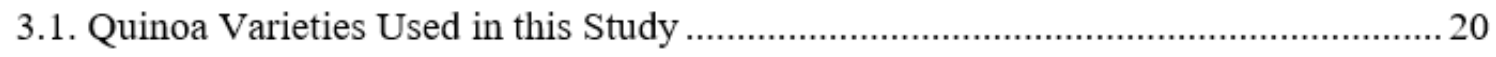

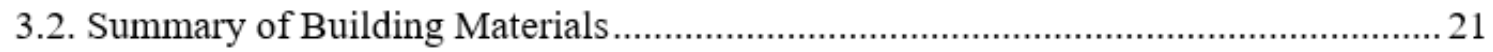

3.3. Summary of Chemical Reagents and Lab Supplies ............................................. 22

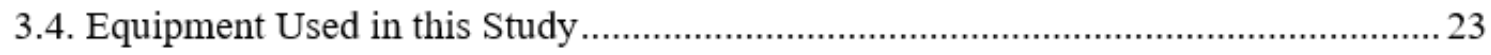

3.5. Experimental Design for Tubular System ............................................................. 38

3.6. Adaptations to the Method of Saponin Quantification ….................................. 42

4.1. Conical System Mass Balance Results ............................................................ 46

4.2. Mass Balance Results from Fluidized Bed …....................................................... 50

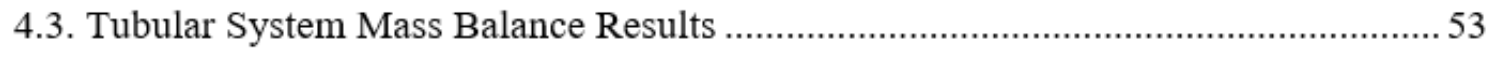

4.4 Saponin Content of Unscarified Quinoa Confirming the Validity of the Adapted



4.5.ANOVA Results from DOE of Processing Conditions .......................................... 58 


\section{LIST OF FIGURES}

Figure

Page

2.1. Pictorial Representation of the Seed Structure of Quinoa (adapted from

(Scanlin and Lewis, 2017 )).

2.2. The Breakdown of the Nutritional Profile of Quinoa from Argentina into the Major Macronutrients, Including Saponins and Tannins. (Adapted from

Gonzalez et al., 1989) 4

2.3. The Change in Levels of Total Saponins, Trypsin and Lipoxygenase in the Different Grain Fractions and Their Proportion to the Whole Grain (Adapted from Ando et al., 2002). 10

2.4. Values on a Dry Basis of Protein, Lipids, Sugar, Dietary Fiber, and Ash in the Different Grain Fraction Components of Quinoa (Adapted from Ando et al., 2002). 10

2.5. Effect of Washing and Abrasion on the Total Saponin Content of Quinoa. 12

2.6. Process Flow Diagram of Quinoa Processing

2.7. System Design of Saponin Removal System Developed by Universidad Privada Boliviana (UPB). 17

3.1. Design Concept of Conical System (not to scale) to Promote Grain-to-Grain Abrasion. 24

3.2. Tubular System Constructed for Saponin Removal. 26

3.3. Design Concept of Fluidized Bed System (not to scale) to Promote Grain-toSurface and Grain-to-Grain Abrasion. 27 
3.4. Fluidized Bed System Constructed for Saponin Removal..

3.5. Design Concept of Tubular System (not to scale) to Promote Grain-to-Surface

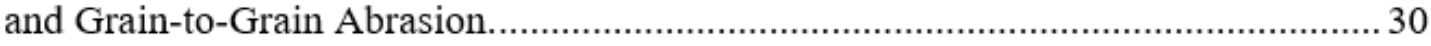

3.6. Tubular Abrasion System Constructed for Saponin Removal. ................................. 32

3.7. Methods Used for the Quantification of Saponin in Quinoa.................................... 44

4.1. Processing Quinoa in a Conical Tank System. ................................................. 47

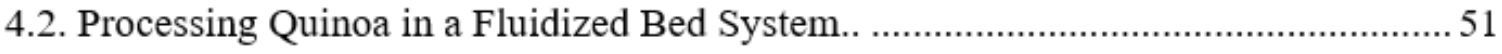

4.3. Processing Quinoa in Tubular System. ............................................................... 52

4.4. Linear Regression of the Standard Curve of Oleanolic Acid at $527 \mathrm{~nm}$...................56

4.5. Percent Saponin in Samples After Processing at Different Time and Mass

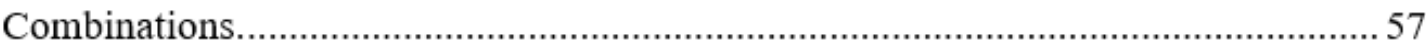

4.6. Percent Saponin in Samples After Processing With Different Surface

Roughness and Different Input Mass. ….............................................................. 59

4.7. Percent Saponin in Samples White Quinoa (A) and Tricolor Quinoa (D) at Different Points in Processing (unscarified, scarified, and scarified-washed)...........61 61

4.8. Difference in Saponin Levels Between Washed and Scarified White Quinoa (A), White Quinoa (B), Washed Tri-Color Quinoa (C), and Washed Tri-Color

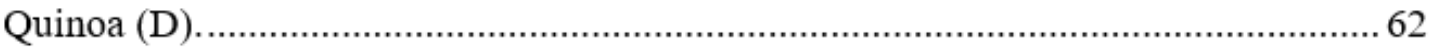




\section{INTRODUCTION}

Ancient grains are rapidly being rediscovered and commercialized to offer wholesome foods to consumers (Scanlin and Lewis, 2017). Most grains contain an outer

hull, bran layer, or undesirable outer coating that must be removed to produce a safe and high-quality consumer product. Energy intensive abrasive techniques and/or a significant amount of washing with water are used to remove the various layers (Arendt and Zannini, 2013). Development of sustainable processing techniques for raw ancient grains is important to provide consumer markets with safe and quality products.

One of the more popular ancient grains in the United States is quinoa. Quinoa is coated with a thin layer of saponins, glycosylated triterpenoids, that produce a bitter flavor when consumed. The average saponin content in commercial varietals from Bolivia average around 2.7\% (Medina-Meza et al., 2016). Quinoa that contains more than $0.11 \%$ by weight is classified as bitter and must be removed from the grain in order to be edible (Nickel et al., 2016). Organoleptic acceptability testing showed that the maximum saponin range for consumer liking is between $0.06 \%$ and $0.12 \%$ (Balize, D;Bertero, D; Nieto, 2015). Current industrial methods for removal of saponins in quinoa utilize a combination of abrasion and extraction with water (Medina-Meza et al., 2016).

\subsection{Statement of Problem}

Industrial methods combine the use of mechanical energy and washing with water to remove the saponins found within the bran. Mechanical processing utilizes abrasion stones and grain to grain friction to remove an outer coating of saponins surrounding the quinoa grain. Washing uses cold water with turbulent flow to extract the hydrophilic saponins located on the surface of the grain (Ridout et al., 1991). The sustainability of 
quinoa processing could be improved by reducing energy input and water usage

necessary for bran (saponin) removal (Balize, D;Bertero, D; Nieto, 2015). Understanding the processing techniques and specific nutrient content of quinoa and its byproducts has the potential to greatly impact human nutrition and promote a more sustainable future.

One study on the removal of saponins has suggested the possibility of removal of saponins greater than $99.9 \%$ by abrasion alone using air pressure in different stream patterns to uniformly mix the grain over 30 minutes (Escalera, 2010). The removal process by grain-to-grain abrasion alone, is thought to provide a more homogenous removal of the bran layer and saponins contained within (Medina-Meza et al., 2016). Further literature review did not indicate the efficacy of this study and the potential for industrial use.

\subsection{Research Question}

This study will address the following research question: How will grain-to-grain and grain-to-surface abrasion affect the processing time to remove saponin from quinoa? In particular, can effective saponin removal be achieved in less than 10 minutes without washing with water?

\subsection{List of Terms}

Quinoa, Saponins, Abrasion, Grain-to-Grain, Saponin Quantification by UVVis Spectrophotometry, Tubular System, Conical System, Fluidized Bed System 


\section{LITERATURE REVIEW}

\subsection{Origin and History of Quinoa}

Quinoa originated around 5000 B.C in the Andean region of South America. The native people of this region, the Incas, consumed quinoa as their main source of food. When the Spanish settled in South America, they introduced new grains to the area, such as wheat, rye and oats. Quinoa was pushed out to the undesirable farming land high in the Andes. Around 1975, commercialization of quinoa began in Bolivia and Peru. Today, Bolivia and Peru account for $90 \%$ of the production worldwide (Scanlin and Lewis, 2017). The price of quinoa rose more than $50 \%$ between 2000 and 2010 as health trends drove its popularity in the EU and US (Arendt and Zannini, 2013). From 2010 to 2013, new quinoa products in the US grew by almost 100\% (Scanlin and Lewis, 2017). The Smithsonian in Washington D.C. named quinoa, "the most nutritious grain in the world" and it is continuing to rise in popularity.

\subsection{Morphology of Quinoa}

Quinoa is genus; Chenopodium and family; Chenopodiaceae (Arendt and Zannini, 2013). It is characterized as a pseudocereal grain, since it is defined as a seed, distinguishing it from most other cereal grains like rice and wheat. The quinoa plant grows between 1 and 3 meters high and is colored in whites, yellows and brownish reds. The fruit, quinoa seed, is flattened and ranges in diameter of 1-3 mm. One seed is produced from each flower. The three main anatomical parts of the fruit are the bran, embryo and perisperm (Figure 2.1). The bran and perisperm are approximately $48 \%$ of the seed weight and contains $22.9 \%$ protein and $7.4 \%$ saponin on a dry basis (Scanlin and Lewis, 2017). 


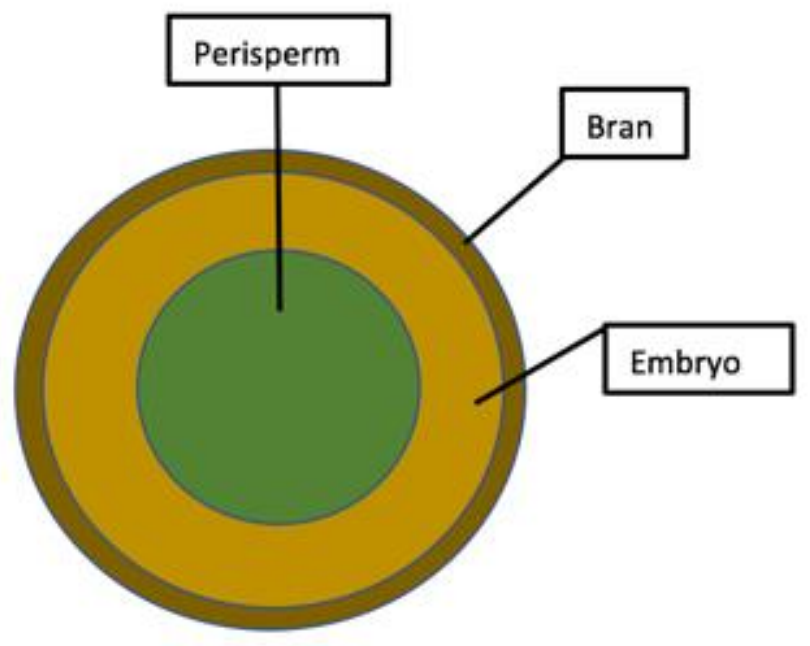

Figure 2.1. Pictorial Representation of the Seed Structure of Quinoa (adapted from (Scanlin and Lewis, 2017 )).

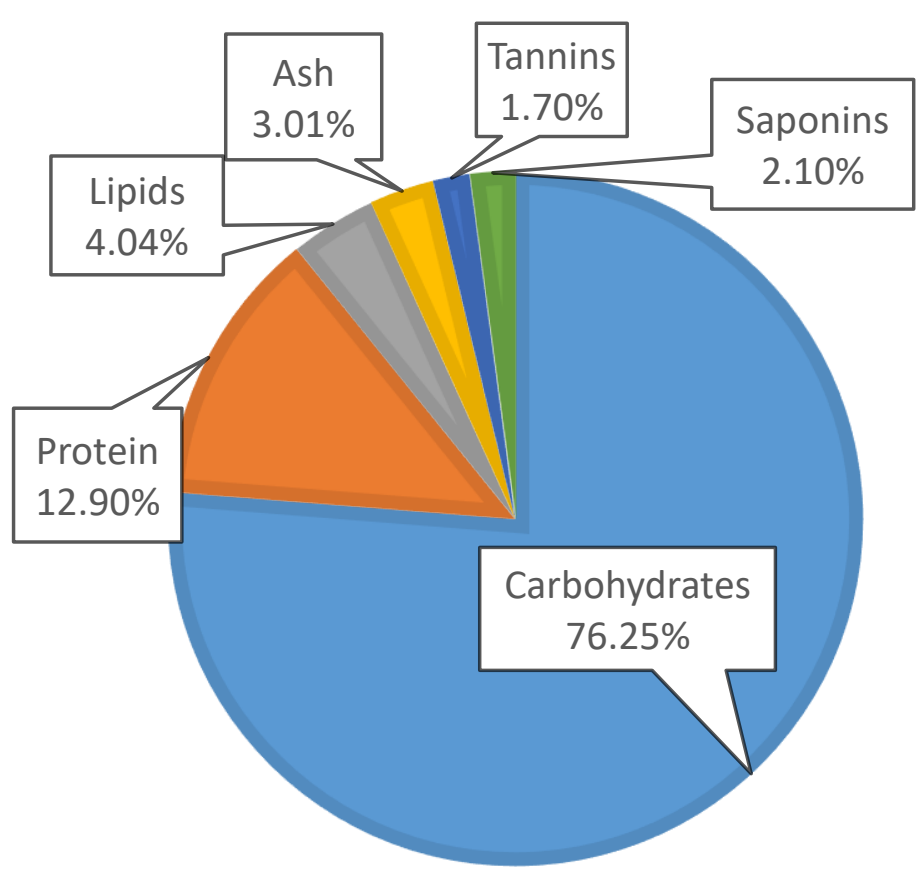

Figure 2.2. The Breakdown of the Nutritional Profile of Quinoa from Argentina into the Major Macronutrients, Including Saponins and Tannins. (Adapted from Gonzalez et al., 1989) 


\subsection{Climate Conditions for Growing Quinoa}

Quinoa grows best in semi-arid regions and is well known as a hardy crop. There is a large genetic variety of quinoa plants and it can be tailored to fit most growing conditions. It can tolerate a temperature range of $-4{ }^{\circ} \mathrm{C}$ to $35^{\circ} \mathrm{C}$, is salt and sand tolerant, drought tolerant and tolerant of atmospheric conditions up to $3800 \mathrm{~m}$ (Scanlin and Lewis, 2017). After commercialization, current yields of quinoa in Peru and Bolivia are around 1.93 t/ha.

\subsection{Composition and Nutrition Value of Quinoa}

The nutritional benefits of quinoa make it a very desirable addition to any diet. Quinoa is most well recognized as a plant-based protein source. The protein content ranges from $12.5-16 \%$ and is higher than any other cereal grain (Figure 2.2). Quinoa is well-balanced in all essential amino acids (EAA) except for leucine but is still adequate enough to meet the nutritional standards of the WHO, FAO, and UNU and is the only plant source that provides all EAAs comparable to casein according to the FAO nutrition standards (Table 2.1). Of the essential amino acids present, quinoa is especially high in lysine and histidine. The protein digestibility of quinoa is around $50.7 \%$ milled compared to a milk casein control of $45.8 \%$. The lipid content of quinoa ranges from $5-7 \%$ with the majority being polyunsaturated (56\%) and monounsaturated (25\%). The fat is well protected from oxidation due to high levels of Vitamin E (Scanlin and Lewis, 2017). The carbohydrate content is mainly starch ranging from $32-69 \%$ depending on varietal and the remainder is comprised of fiber. Quinoa starch gelatinizes between $55^{\circ} \mathrm{C}$ and $73{ }^{\circ} \mathrm{C}$. Amylopectin comprises a large amount of the starch and provides a hindrance to retrogradation with superior freeze thaw stability. Maltose, D-ribose and D-galactose are 
the main sugars with low levels of glucose and fructose. The fiber content ranges from 8$13 \%$, of that, $78 \%$ is insoluble and $22 \%$ is soluble (Ando et al., 2002). The soluble fiber range is similar to that of fruits and vegetables opposed to that of cereal grains. Quinoa is rich in vitamins of which include; vitamin A precursor $\beta$-carotene, thiamin/vitamin B1, riboflavin/ vitamin B2, niacin/vitamin B-3, ascorbic acid/vitamin C, folic acid/vitamin B9 and vitamin E B6, and pantothenic acid (Kozioł, 1992). Quinoa does not contain any fractions of gluten, it does contain some very small amount of prolamins, and is considered to be allergen free (Scanlin and Lewis, 2017). However, quinoa contains various anti-nutritional components which are phytate phosphate, saponins, trypsin and lipoxygenase. Saponins are the largest group by mass and contribute the most to the bitter taste of quinoa.

Saponins function in quinoa is very important in preserving the seed of the quinoa plant from insect and fungal attack (Simmonds, 1965). The saponins are located in the pericarp (bran) of the grain and can be removed by abrasion polishing or washing with water. Typical removal reduces the saponins to around $0.11 \%$ with a yield loss of $5 \%$ (Scanlin and Lewis, 2017). It is difficult to remove all of the saponin without removing all of the pericarp (bran). Saponins are composed of various structural arrangements of triterpenoids or steroid glycosides. The variation results from the number and position of sugar units attached to the hydrophobic aglycon. Quinoa saponins are glycosylated triterpenoids. The most common saponin by mass is phytolaccagenic acid (Medina-Meza et al., 2016). Other saponins commonly found in lower quantities are oleanolic acid and hederagenin saponins (Ridout et al., 1991).The typical concentration of saponins in quinoa ranges from 0.01\%-5\% (Medina-Meza et al., 2016). Quinoa that contains more 
Table 2.1. Amino Acid Composition (mg/g Protein) of the Proteins in Quinoa and Other Cereal Grains in Comparison to the WHO/FAO/UNU Scoring Pattern for Young Children (6 Months to 3 Years) and Older Children, Adolescent, and Adult (3-10 Years).

\begin{tabular}{|c|c|c|c|c|c|c|}
\hline \multirow[t]{2}{*}{ Amino Acid } & \multicolumn{4}{|c|}{$\mathrm{mg} / \mathrm{kg}$ protein } & \multicolumn{2}{|c|}{$\begin{array}{c}\text { WHO/FAO/UNU Scoring patterı } \\
\text { (mg/kg protein })\end{array}$} \\
\hline & Corn $^{a}$ & Quinoa $^{\mathrm{b}}$ & Rice $^{c}$ & Wheat ${ }^{d}$ & Young Children & Adult \\
\hline Alanine & 75 & 42 & 58 & 36 & NA & NA \\
\hline Arginine & 50 & 77 & 83 & 47 & NA & NA \\
\hline $\begin{array}{l}\text { Aromatic amino acids } \\
\text { (EAA) }\end{array}$ & 90 & 61 & 86 & 78 & 52 & 41 \\
\hline Aspartic acid & 70 & 80 & 94 & 51 & NA & NA \\
\hline Glutamic acid & 188 & 132 & 195 & 317 & NA & NA \\
\hline Glycine & 41 & 49 & 46 & 42 & NA & NA \\
\hline Histidine (EAA) & 30 & 29 & 24 & 23 & 20 & 16 \\
\hline Isoleucine (EAA) & 36 & 36 & 43 & 36 & 32 & 30 \\
\hline Leucine (EAA) & 123 & 59 & 83 & 68 & 66 & 61 \\
\hline Lysine (EAA) & 28 & 54 & 36 & 27 & 57 & 48 \\
\hline Proline & 87 & 55 & 47 & 102 & NA & NA \\
\hline Serine & 47 & 40 & 53 & 46 & NA & NA \\
\hline Sulfur amino acids (EAA) & 39 & 36 & 44 & 42 & 27 & 23 \\
\hline Threonine (EAA) & 38 & 30 & 36 & 29 & 31 & 25 \\
\hline Tryptophan (EAA) & 7 & 12 & 12 & 13 & 8.5 & 6.6 \\
\hline Valine (EAA) & 51 & 42 & 61 & 44 & 43 & 40 \\
\hline
\end{tabular}

(EAA- Essential Amino Acid) ${ }^{\mathrm{a}}$ Corn grain, yellow, No. $20014 .{ }^{\mathrm{b}}$ Quinoa, uncooked, No. $20035 .{ }^{\mathrm{c}}$ Rice, white, long-grain, regular, raw, unenriched, No. 20444. ${ }^{\mathrm{d}}$ Wheat, hard red winter, No. 20072. ${ }^{\mathrm{a}, \mathrm{b}, \mathrm{c}, \mathrm{d}}$ Source: USDA National Nutrient Database for Standard Reference Release 28. Retrieved Oct. 16, 2015 (adapted from (Scalin and Lewis, 2017)) . Bold lettering signifies essential amino acids. 
than $0.11 \%$ by weight is classified as bitter and must be removed from the grain in order to be pleasing to the taste (Nickel et al., 2016).Organoleptic acceptability testing showed that the maximum saponin range for consumer liking is between $0.06 \%$ and $0.12 \%$ (Balize, D;Bertero, D; Nieto, 2015). Breeding has become a new focus in saponin reduction within quinoa. New varietal strains of "sweet' quinoa are being developed. The average saponin content in commercial varietals from Bolivia average around $2.7 \%$ saponins. New varietals are being produced with an average of less than $1 \%$ saponins to reduce the amount of processing required (Medina-Meza et al., 2016).

\subsection{Processing of Quinoa}

\subsubsection{Primary Processing}

Industrial processing of quinoa is essential to provide a consumer or supplier with clean quinoa that is free of impurities as well as saponins. The grain being processed includes both hand harvested grain as well as combine harvested. The processing process is set up to handle conditions from both harvesting methods, although some steps may not be as necessary as others. Preliminary sorting is completed with different sized sieves. A plate perforated with $3 \mathrm{~mm}$ diameter openings topped with a woven mesh of 1.2 mm between threads separates out the 5 products streams. The five streams include: 1 . particulate matter, 2. light course impurities, 3. first grade grain, 4. second grade grain and 5. heavy impurities. Particulate matter includes dust from transport and harvest as well as saponins that have been removed from grain to grain contact during harvesting and transportation. Light course impurities are pieces of the quinoa plant or twigs and leaves collected during harvest or transport. 
First grade grain is quinoa that has a diameter greater than $2.2 \mathrm{~mm}$ and accounts for $90-95 \%$ of the grain processed. Second grade grain has a dimeter less than $2.2 \mathrm{~mm}$. This grain is returned to the farmer or sold for a lower price. Heavy impurities are stones and are most prevalent in quinoa that is hand harvested. The grain is then stored in silos or totes until ready to be processed.

\subsubsection{Removal of Saponins}

An understanding of the nutritional composition of quinoa and the high percentage of saponins present, reveal why processing is required to remove saponins and create an edible grain. Whole quinoa grain is broken down into three main structural components: bran, embryo, and perisperm. The bran is the outermost layer surrounding the embryo. The embryo covers the perisperm, the innermost layer, like a headband. The bran is removed during processing as it contains $86 \%$ of saponins compared to the other grain fractions (Figure 2.3). The embryo and perisperm contain 11\% and 3\% saponins, respectively (Figure 2.3).

The two main forms of saponin removal are abrasion and washing. Abrasion is most common as it removes the outer bran layer by mechanically rubbing the grain together against itself or a stone (Balize, D;Bertero, D; Nieto, 2015). Often processing techniques involve a wash step following abrasion to further reduce the level of saponins (Ridout et al., 1991). However, for some grains that have higher amounts of saponins, if a wash step is not employed, the embryo is the next outer layer after the bran that is partially reduced (Balize, D;Bertero, D; Nieto, 2015). The embryo is the largest source of nutritional elements as it contains $57 \%$ protein, $49 \%$ lipids, $20 \%$ sugar, $45 \%$ dietary fiber and $51 \%$ ash of the whole grain (Figure 2.4). Removal techniques that leave the embryo 


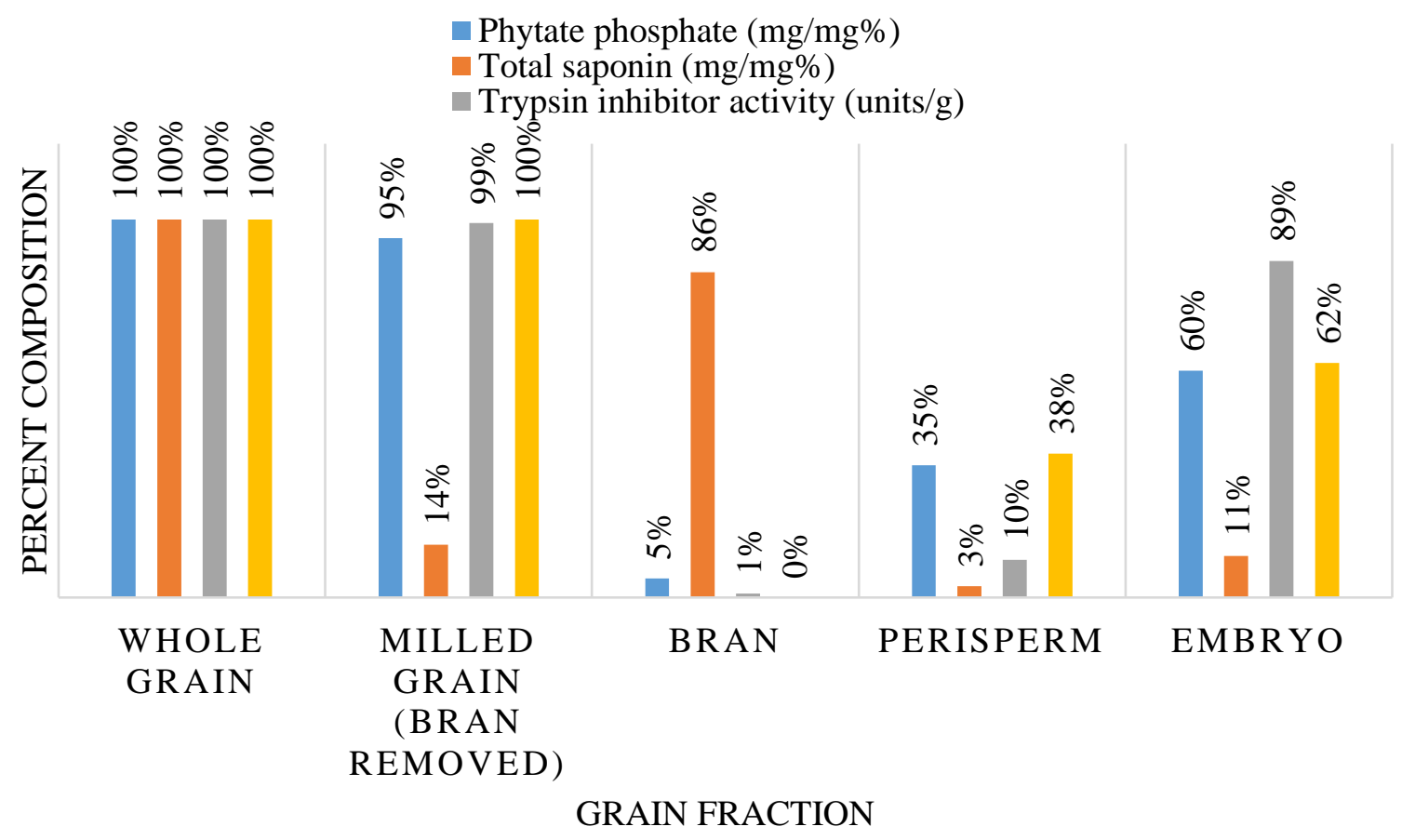

Figure 2.3. The Change in Levels of Total Saponins, Trypsin and Lipoxygenase in the Different Grain Fractions and Their Proportion to the Whole Grain (Adapted from Ando et al., 2002).

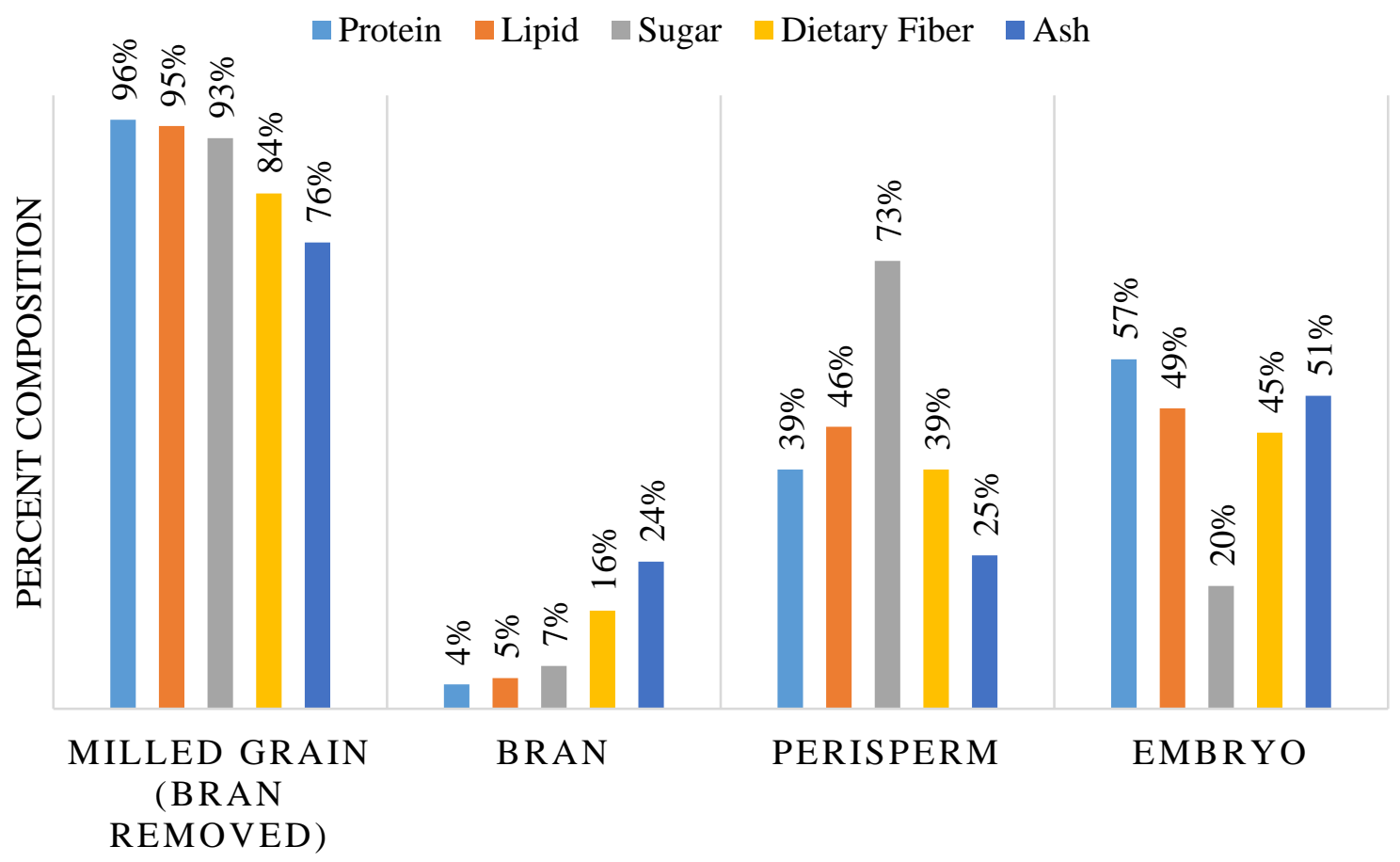

GRAIN FRACTION

Figure 2.4. Values on a Dry Basis of Protein, Lipids, Sugar, Dietary Fiber, and Ash in the Different Grain Fraction Components of Quinoa (Adapted from Ando et al., 2002). 
intact, preserve the complete nutritional profile of quinoa. Washing for saponin removal takes significantly more time to process than abrasion. Washing alone ranges from 5 to 30 minutes a cycle, while abrasion alone ranges from 30-150 seconds (Nickel et al., 2016; Balize, D;Bertero, D; Nieto, 2015) ). Thirty minutes of washing with agitation reduced the saponin content of $1 \%$ to $.23 \%$ (Figure 2.5 ). Additional washing continues to remove saponins, but not at the same rate. After an additional 60 minutes of washing total saponin content was reduced to $0.18 \%$ (Figure 2.5). Abrasion alone after 30 s reduced saponin levels from $1.19 \%$ to $.45 \%$. After an additional 2 min the saponin level was reduced to $0.21 \%$ (Figure 2.5). Washing alone increased the saponin percentage of oleanolic acid, while decreasing phytolaccagenic acid. On the other hand, abrasion decreased the percentage of oleanolic acid, while increasing phytolaccagenic acid. These differences are correlated to the chemical structure of the specific saponin and the location within the bran layer. Another study washed quinoa under running water with manual rubbing for $15 \mathrm{~min}$ and found a reduction of $3.33 \%$ to $2.75 \%$. Hydrating the quinoa without manual rubbing increased the saponin levels from $3.33 \%$ to $3.63 \%$. Washing combined with cooking reduced the original saponin level to $2.5 \%$ (Nickel et al., 2016).

The use of cold water as being the most important factor alongside agitation or rubbing was noted in both studies and warm water was attributed to the lower reduction of saponins in the second study. The use of both water and abrasion is useful in further reducing saponins to an acceptable level and reducing the different types of saponins present. Quinoa's only need for processing is to remove the outer coating of saponins present on all varieties of quinoa. Hulling or scarification removes the outer layer of 

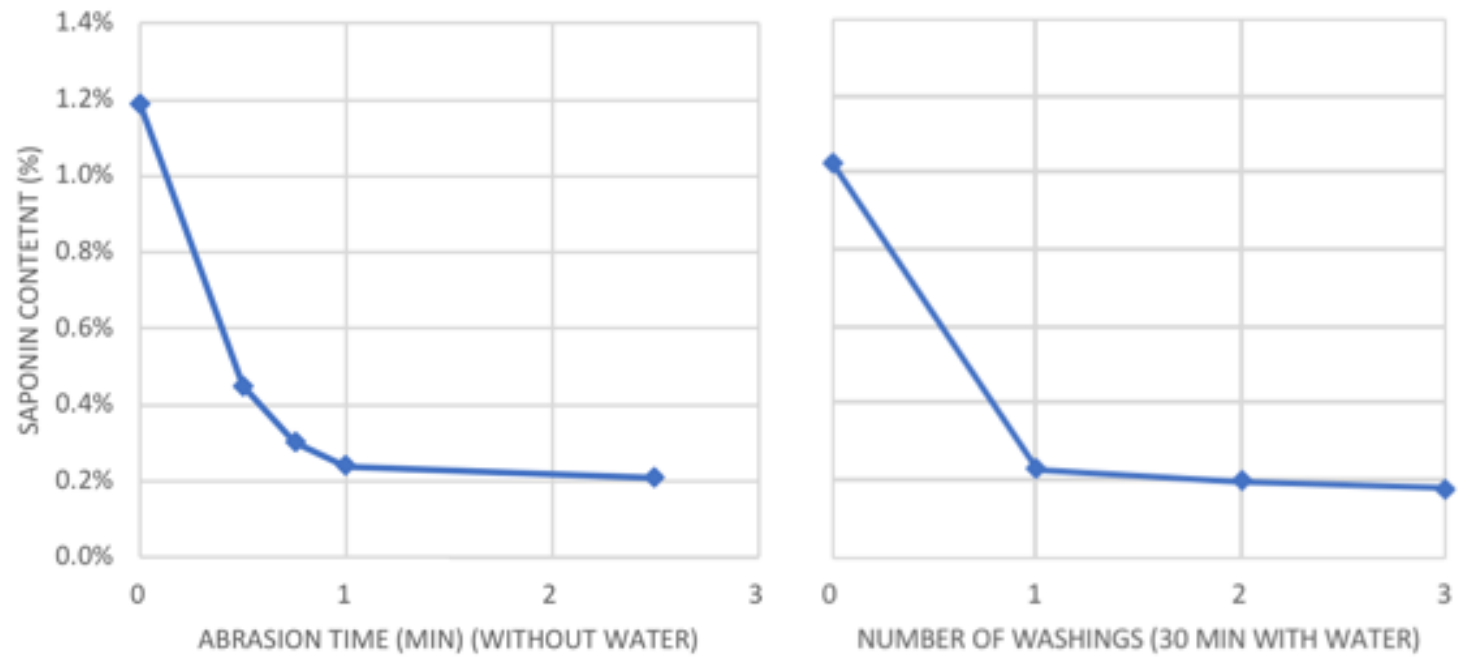

Figure 2.5. Effect of Washing and Abrasion on the Total Saponin Content of Quinoa. Washing was carried out on material from the 1987 harvest (original saponin content $1.03 \%$ ). Abrasion was conducted on the 1988 material (original saponin content $1.19 \%$ ). (Adapted from Ridout et al., 1991) 
saponins and some of the bran by mechanical abrasion. A cylindrical drum with metal protruding ribs (8-12 $\mathrm{mm}$ wide) mounted to a revolving rotor (1200-1600 rpm) presses the grains against each other to produce abrasion. The intense friction against the grains provides uniform wearing down of the bran, and reduces the damage done to the embryo. The bottom of the cylindrical drum is perforated with a metal plate to allow saponins, in powder form, to fall through. The abrasion process removes $90-95 \%$ of saponins.

Abrasion processing is often the only form of processing done to quinoa as it removes the majority of saponins. Washing with water can be left to the consumer to be performed before cooking or done in an industrial setting. Washing requires both water and energy intensive drying to reduce the moisture content to prevent mold growth and maximize shelf life. Quinoa is fist soaked in water (time dependent on processor) and then washed. The grain flows in a laminar trajectory through a turbulent flow of water. This technique ensures first in first out and works with a continuous flow system. During the wash cycle, quinoa is in contact with water for about $5 \mathrm{~min}$. The wash cycle requires 1300 to 1850 gallons of water per ton of quinoa. This run off is contaminated with saponins and cannot be reused throughout the process. The grain is then rinsed and centrifuged. The water stream from the centrifuge is recycled back into the washing process. The wet grain needs to be dried in order to preserve its shelf life and continues to a set of different dryers.

The grain passes through a set of drying tables that have warm air passed up through the bottom of the table. A granulometric sorter is used to separate the grains by size. Different colors of quinoa are separated out using an optical-pneumatic sorter. The 




Figure 2.6. Process Flow Diagram of Quinoa Processing 
sorting process takes two to three runs to achieve adequate color sorting. Typical yield loss during processing is acceptable at 5\% (Figure 2.6).

\subsubsection{Research in Saponin Removal}

Industrial saponin removal systems utilize both abrasion and contact with water to remove saponins from quinoa. Small scale abrasion and wash systems have been constructed that are able to process $12 \mathrm{~kg}$ of quinoa in 7 minutes. However, small scale system times have not been achieved in large scale industrial use.

Researchers have been working to develop methods of removal that do not use water. "In 2010, a group of researchers at the Universidad Privada Boliviana (UPB) developed a laboratory model of a novel application of the spouted bed that is commonly used to dry cereal grain (Figure 2.7). In less than 30 minutes, the dry process reduced the saponin concentration in the grains to $<0.01 \%$ (Escalera Vásquez et al., 2010)." The method for saponin quantification after processing was not stated. This method forces air through the center of the quinoa, creating a central channel. The grain continues to shoot up the center channel, fall down onto the top of the bed of quinoa at the top of the container and then make its way back down until it is forced back up the central channel. This design utilizes grain to grain friction as the primary driver of removal.

\subsubsection{Quantifying Saponin Content}

Few instant methods exist for the quantification of saponins in quinoa. The afrosimetric method is one of the quantifiable rapid methods of extraction that exists for measuring saponin content in a substance. Raw quinoa is agitated with water which produces a layer of foam on the surface of the quinoa water mixture. The height of the foam that remains after 15 minutes is used to quantify the amount of saponins present 

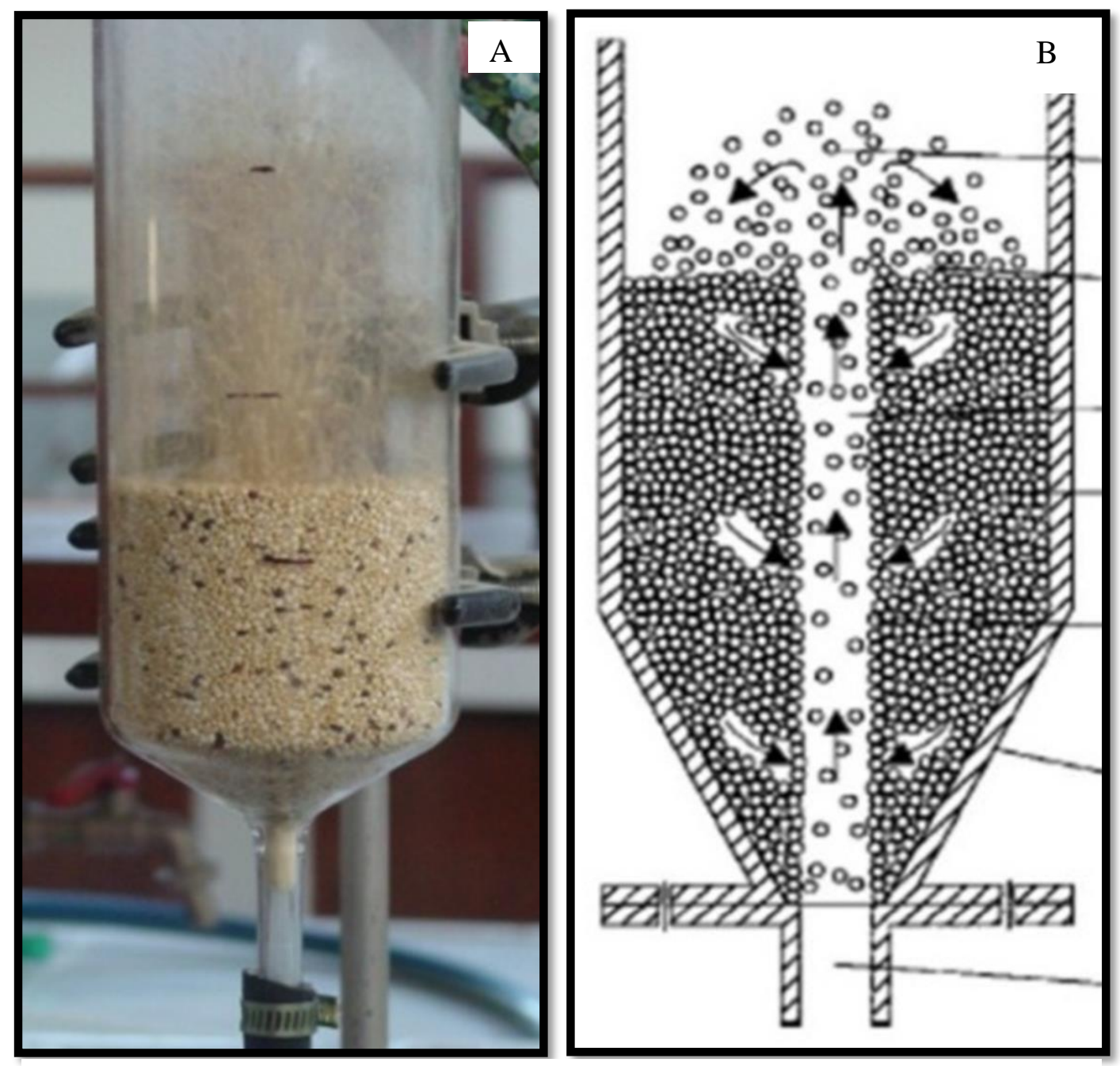

Figure 2.7. System Design of Saponin Removal System Developed by Universidad Privada Boliviana (UPB). A- Operation of saponin removal system. B- System design of saponin removal system. (Pictures sourced from Escalera Vásquez et al., 2010) 
(Medina-Meza et al., 2016). This provides a subjective estimate for measuring the final product during processing but is not as precise as other laboratory methods. The most current lab methods of extraction and quantifying saponin are by UV-Vis Spectrophotometry and GC Mass Spectrophotometry reported by Ilce G. Medina-Meza, Nicole A. Aluwi, Steven R. Saunders, and Girish M. Ganjyal (2016).

\subsection{Consumption of Quinoa}

Quinoa is consumed in many different ways, typically dependent on the geographic location. The most common consumption of quinoa is cooked in the whole grain form. Quinoa grains in the whole form are also consumed pasteurized, sprouted, toasted, and boiled. The grain is also milled as flour, extruded, puffed, processed into flakes or fermented as a beverage. In South America, a quinoa drink, similar to rice milk, is a popular way to consume quinoa. 


\section{MATERIALS AND METHODS}

\subsection{Materials}

The quinoa used during experimentation was a blend of three different quinoa varieties and are listed in Table 3.1. The three varieties are structurally different and have different levels of saponin. Current industry practice is to grow and process the grain as a blend. Sampling procedures were developed in order to ensure that samples were representative of the population and current industry practice. The quinoa was harvested and combined into 1 large storage bin. Three 25-pound bags were filled from the bin and stored at California Polytechnic State University San Luis Obispo under refrigeration at $50^{\circ} \mathrm{F}$.

The materials listed in Table 3.2. were used to fabricate the different saponin removal systems. Chemical reagents were sourced from both Fisher Scientific and Sigma Aldrich. The equipment listed in Table 3.3. was used to carry out fabrication and experimentation of the saponin removal systems and the quantification of saponin.

\subsection{Methods}

\subsubsection{Design and Fabrication of Abrasion Equipment}

\subsubsection{Conical System}

Past research in saponin removal provided the basic concept of design (Figure 3.1.). The design is based on grain-to-grain friction principals at work and was adapted from the work of Escalera Vásquez et.al, (2010). A conical tank was inverted to replicate the design of this system. The system design focuses on grain to grain abrasion. A detailed design is shown in Figure 3.1.

A 3-gal carboy was inverted to make a conical shaped container. A 3-in diameter 
Table 3.1. Quinoa Varieties Used in This Study.

\begin{tabular}{|c|c|c|c|}
\hline Quinoa Variety & Procured from & Supplier's Address & Purpose \\
\hline Unscarified Tri Color Quinoa & Lundberg Family Farms & 5311 Midway, Richvale, CA 95974 & $\begin{array}{c}\text { Saponin Removal } \\
\text { Experimentation }\end{array}$ \\
\hline $\begin{array}{l}\text { Washed White Quinoa } \\
\text { Scarified White Quinoa } \\
\text { Unscarified White Quinoa }\end{array}$ & Company A & N/A & \\
\hline $\begin{array}{l}\text { Washed White Quinoa } \\
\text { Washed and Rinsed Tri Color } \\
\text { Quinoa }\end{array}$ & Company B & N/A & 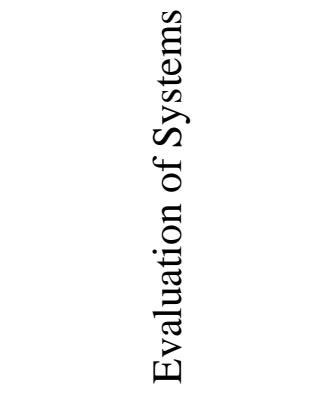 \\
\hline $\begin{array}{l}\text { Washed Tri Color Quinoa } \\
\text { Scarified Tri Color Quinoa } \\
\text { Unscarified Tri Color Quinoa }\end{array}$ & Company D & N/A & \\
\hline
\end{tabular}


Table 3.2. Summary of Building Materials.




Table 3.3. Summary of Chemical Reagents and Lab Supplies.

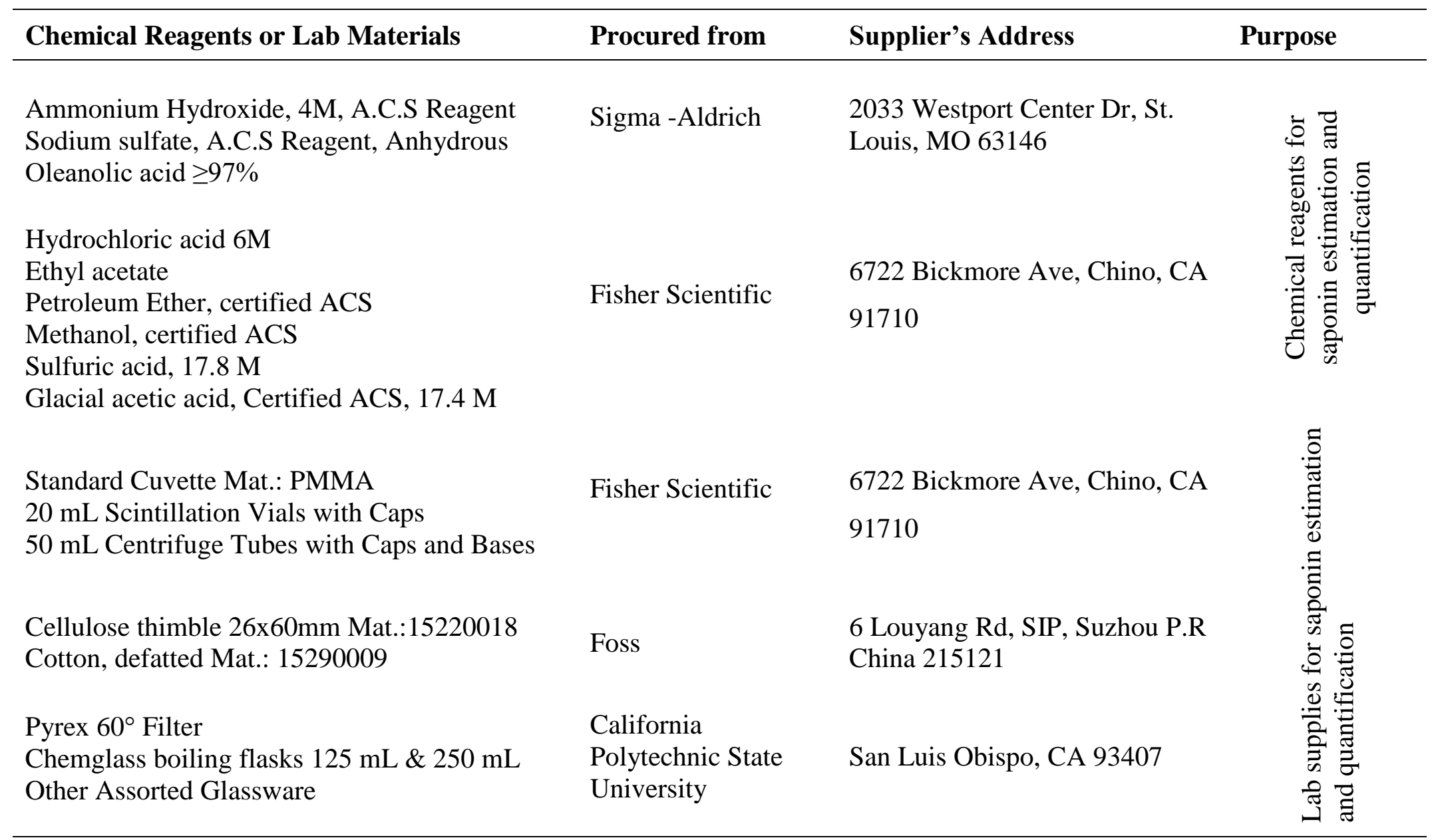


Table 3.4. Equipment Used in This Study.

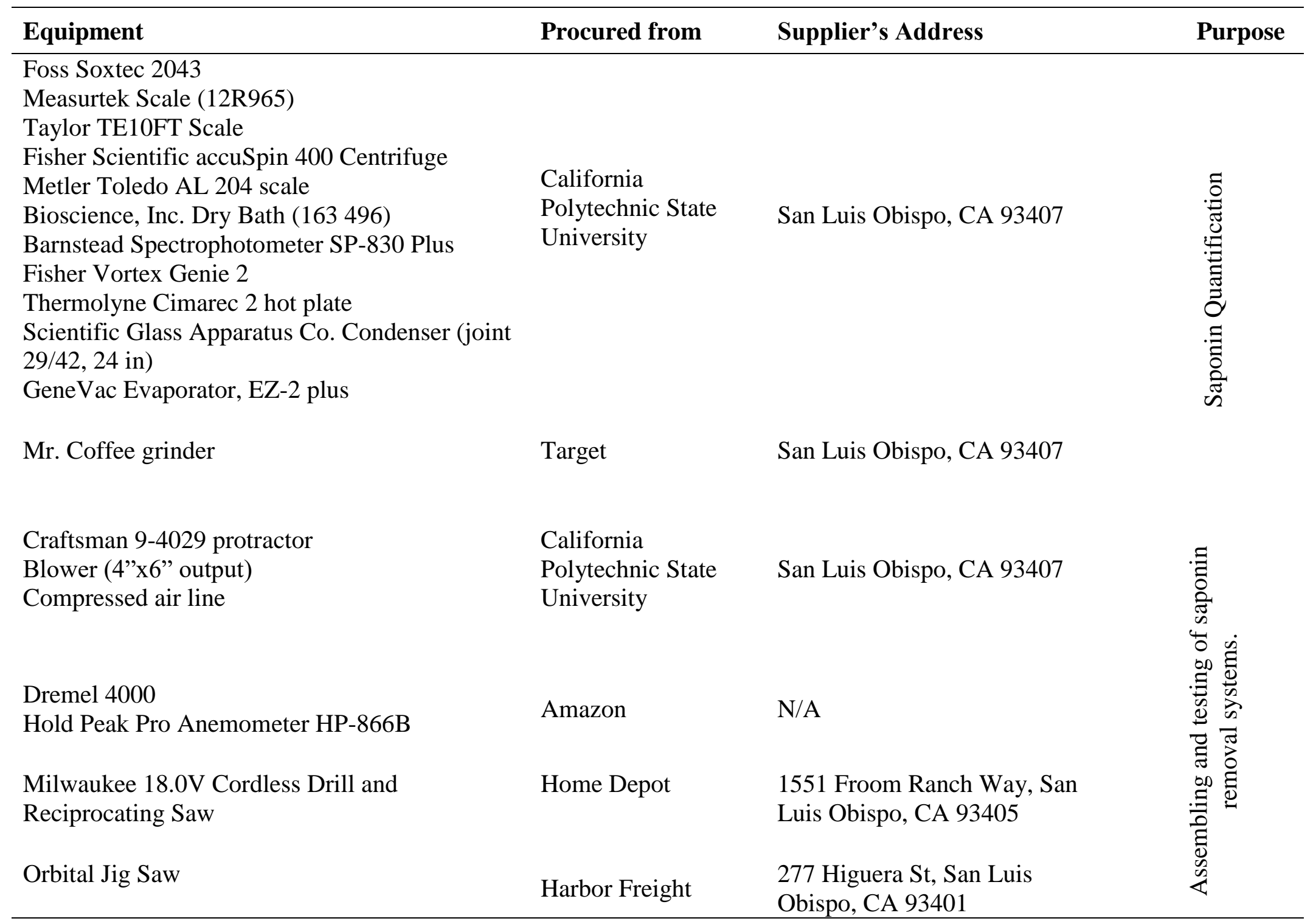




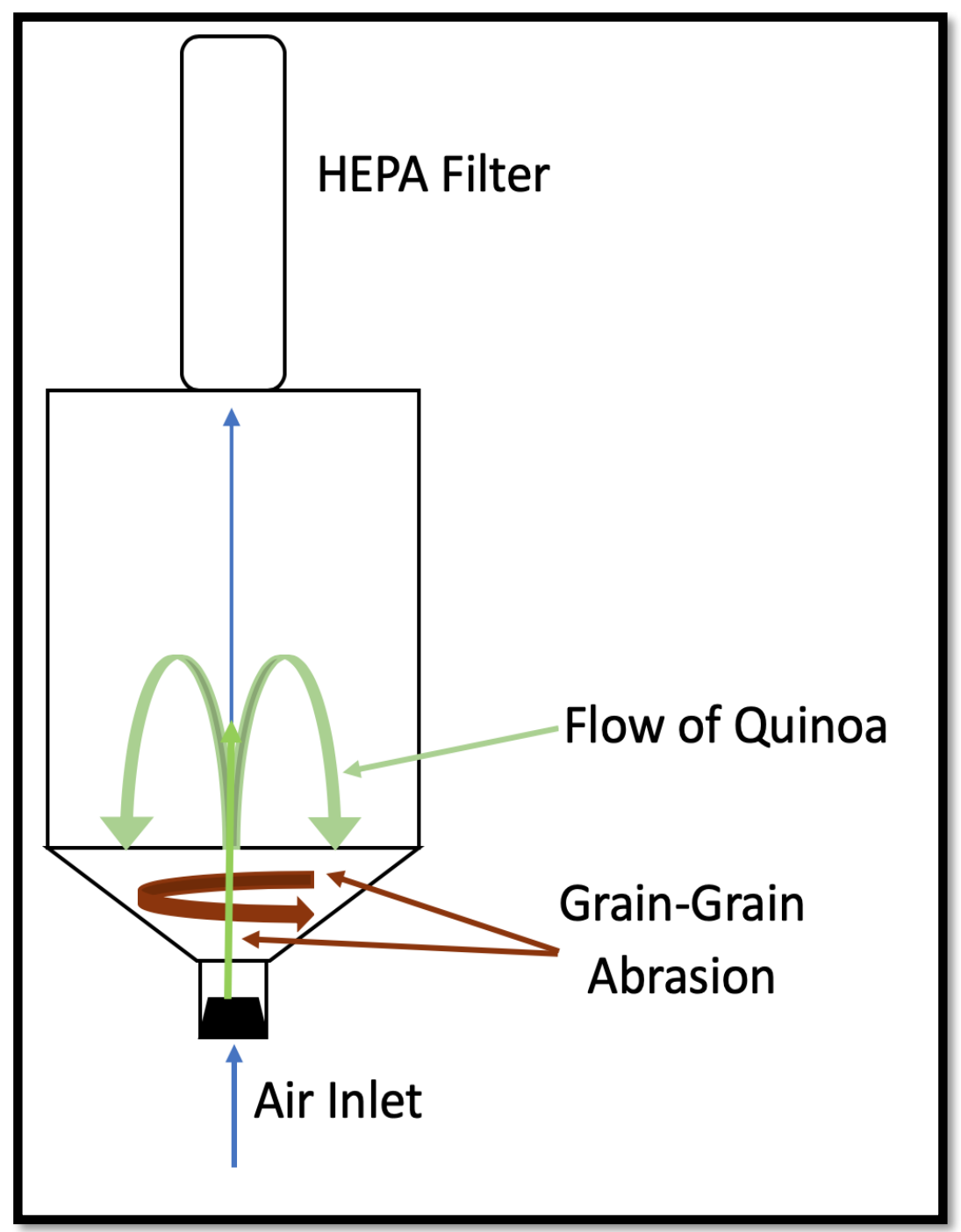

Figure 3.1. Design Concept of Conical System (not to scale) to Promote Grain-to-Grain Abrasion. 
hole was cut out of the top of the carboy and a vertical HEPA filter was attached. The bottom of the tank was plugged with a rubber carboy bung (Figure 3.2.A). The bung was drilled out with a 1/4-inch hole and a 1/4-inch air hose fitting was glued into the hole. The carboy was mounted to a wooded frame for support and to keep the tank level. The tank was not attached to the wood, but rested on the top of the tank, so the tank could easily be removed for cleaning (Figure 3.2.B). The air was sourced from a central air composer and passed through an air filter and moisture trap. The air was then passed through a digital pressure gauge before it reached the bottom of the tank (Figure 3.2.C). An air filter was constructed from metal mesh that was glued into a 12 -inch cylinder with a 3 -inch diameter. HEPA filter was wrapped around the mesh, covering all sides except the bottom of the filter that was firmly inserted into the top of the tank. A piece of wire was wrapped around the filter 8 times to keep the filter snug against the metal mesh. Samples were loaded in through the top and then the air filter was snugly inserted back into the hole.

\subsubsection{Fluidized Bed System}

In an effort to reduce processing times even more to an industrial scale, (of 7 minutes or less) the addition of friction for the surrounding surfaces was integrated into a fluidized bed system. This system was designed to increase the constant rubbing of the grain on the surface of the bed sides (Figure 3.3.). The increase in surface area to mass was designed to increase external surface abrasion as well as promote grain to grain abrasion. Plexiglass panels were cut to make a 36x6x12-inch rectangle (Figure 3.4.A). The ends were glued to 1-inch aluminum angle iron. The bottom side was then glued to a 

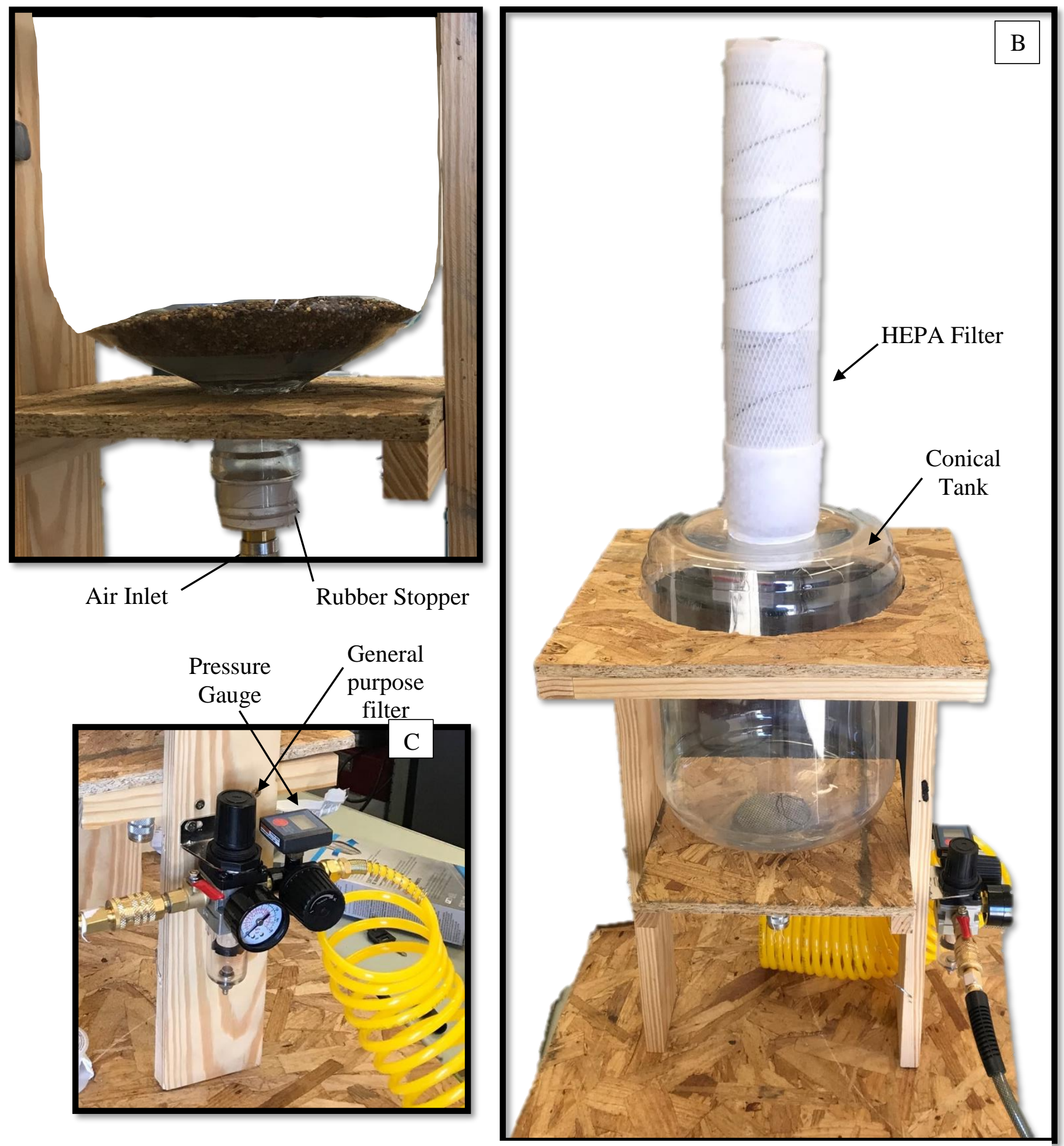

Figure 3.2. Tubular System Constructed for Saponin Removal. A: Connection of pressurized air to the tank. B: Overview of tank design. C: Pressure regulating system. 


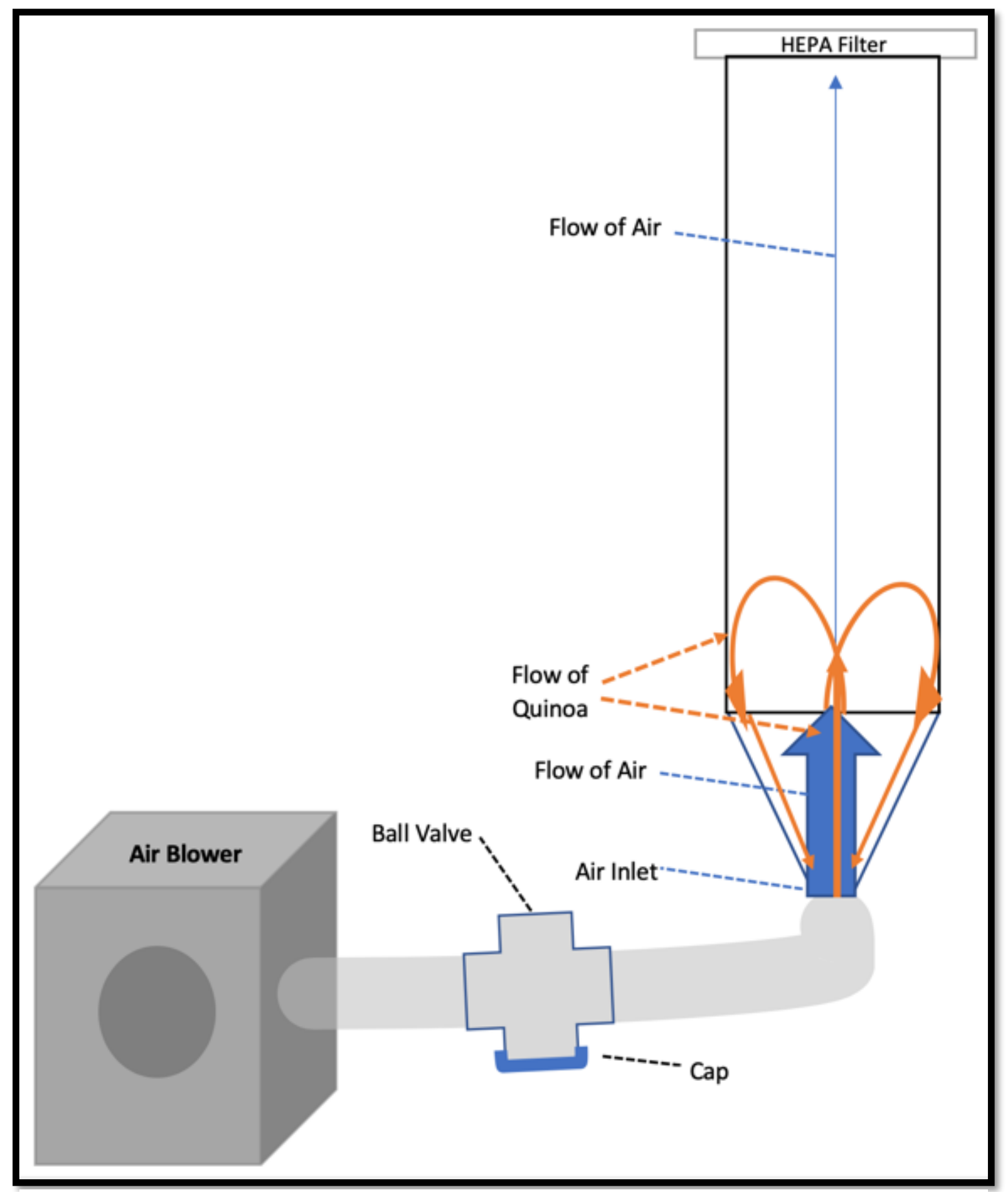

Figure 3.3. Design Concept of Fluidized Bed System (not to scale) to Promote Grainto-Surface and Grain-to-Grain Abrasion. 



Figure 3.4. Fluidized Bed System Constructed for Saponin Removal. A: Side view of system not connected to the blower. B: Connection of air to the system. C: Blower setup. 
6x12-inch air register. The inside seam of the air register and the plexiglass was smoothed out with calking to prevent quinoa from collecting in the joint. The air register was connected to a 6-inch to 4-inch reducer (Figure 3.4.B). At the bottom of the reducer (4-inch side) fine screen mesh was duct taped around the bottom of the reducer to prevent quinoa from falling into the blower. All internal seams of the air register were calked and smoothed. The reducer was connected to a 2 -foot duct that was connected to an industrial blower. A double layer of drain pipe sock was inserted in between the connection to the blower to reduce the flow of air. The blower was fitted with two outlets (Figure 3.4C). One was connected to the fluidized bed and the other to a 2 -inch ball valve which was used to control the air flow. The system was built onto a wooden frame that held the system 30-inch above the ground. The top of the system was mounted with a 1-inch angle iron frame that fit to the outside dimensions of the top of the rectangle. The top of the angle iron frame was fitted with padded tape to allow for a tight seal with an air filter. A 6x12-inch HEPA filter was placed onto the top of the angle iron and the sides were clamped down tight with spring clamps.

\subsubsection{Tubular System}

A third system to provide additional surface abrasion was conceptually developed as detailed in Figure 3.5. The surface of the pipe was acted upon by a steel brush drill attachment to produce a rough surface that could increase surface abrasion as the grain flows up and down the tube. As the grain is flowing throughout the tube it is also being forced across a long bed of quinoa to provide grain to grain abrasion. A 4-foot clear polycarbonate tube (17/8" ID x 2" OD x 1/16" Wall) was fitted with pipe fittings on either side. The bottom side of the pipe was fitted with a 2"x 1.5" PVC bushing. The 




Figure 3.5. Design Concept of Tubular System (not to scale) to Promote Grain-toSurface and Grain-to-Grain Abrasion. 
inside 1.5" diameter was sand down with a Dremel and sanding wheel attachment until the pipe could be inserted into the bushing. The top side of the tube was fitted with a 1.5"x1.25" PVC bushing. The inside of the tube (first 2-feet) was roughed up with a wire brush attached to a drill for 5 minutes. The bottom of the tube was plugged with a rubber carboy bung. The bung was drilled out with a $1 / 4$-inch hole and a 1/4-inch air hose fitting was glued into the hole. The air was sourced from a central air compressor and passed through an air filter and moisture trap. A 4-inch piece of angle iron was taped to the bottom of the tube (12 inches from the bottom) to allow the pipe to stay in place during operation. A 16x16x5-inch box was used as a frame to hold the tube in place. One of the 5-inch sides was cut down, so when the tub was placed in the box, a 32-degree angle was produced. A 1-inch flexible pipe was fitted to the end up the tube. The tube fed into a 5gallon bucket through a small hole in the lid. A metal weight was wrapped around the bottom of the tube to ensure it was held below the water's surface. The bucket was placed inside a large plastic bag and then onto a scale (Figure 3.6).

\subsubsection{Experimentation}

\subsubsection{Preliminary Experiments with Conical, Fluidized Bed, and Tubular Systems}

The objective of the preliminary experiments was to determine which system (Conical or Fluid Bed or Tubular) will have maximum saponin removal capacity. Several processing conditions were tried for each system. The combination of parameters that were chosen best aligned with the design of the system and optimized the performance of the system. Each set of process parameters were unique to the different system due to fabrication limitations and available facility/equipment at Cal Poly SLO. Each system was tested at the parameters that yielded the best results in triplicate. The response 




Figure 3.6. Tubular Abrasion System Constructed for Saponin Removal. 
variables collected during preliminary experimentation were pictures and mass balance. Pictures were taken of visual observations of the following before and after processing: quinoa, filters, processing systems and saponin containing fractions. Pictures of the system were also taken during operation. The mass balance was calculated using before and after weights of the input grain mass, processed grain mass and the sum of saponin containing fractions (sieved particles less than 0.0559-inch diameter, particles collected in the filter and residual particles remaining in the system) (section 3.2.2.1.4.2) and reported as percent yield loss.

\subsection{Conical System.}

The tank was removed from the wooden stand, weighed and recorded. New pieces of HEPA filter sheets were wrapped around a metal mesh cylinder. The total weight of the HEPA filter was weighed on a scale and recorded. 300 grams of Lundberg Family Farms Tri-Color Quinoa was weighed and recorded.

The rubber stopper was attached to the air inlet and firmly pressed into the bottom of the conical tank. The weighed quinoa was added to the system from the top. The HEPA filter was inserted into the top of the tank, 2-inches below the line of the tank. The digital psi gauge was set to $11 \mathrm{psi}$. The ball valve was opened, and the system was run for 15 minutes.

The rubber stopper was disconnected from the air and the tank removed from the wooden stand. A mesh sieve of diameter 0.0559-inch and catch basin were weighed individually in order to calculate the total amount recovered at each level. The tank was placed over the sieve and catch basin and the rubber stopper removed. All of the quinoa and dust were shaken onto the sieve. The sieve was shaken for 2 minutes and amount 
collected at each level was measured and recorded. The tank was placed on a scale, measured and recorded to account for dust remaining on the inside of the tank. The HEPA filter was removed, weighed and recorded. A mass balance was calculated using the weights of quinoa and saponin containing fractions collected in the sieve and catch basin as well as the dust collected in the HEPA filter and the residual dust in the tank. The test was performed in triplicate at 15 minutes with 300 grams at 11 psi.

\subsection{Fluidized Bed System.}

The flex ducting, reducer, and system base (air register and plexiglass rectangle) were weighed, photographed and recorded before experimentation to account for any dust that may have collected. 800 grams of Lundberg Family Farms Tri-Color Quinoa was weighed, photographed and recorded. A 12"x12" HEPA air filter was weighed, photographed and recorded.

The bottom of the reducer was attached to the flex ducting and sealed with duct tape. The blower was turned on and the flow of air was measured from the top of the reducer and adjusted to different volumetric flows using the ball valve. The volumetric flow was calculated using the 6-inch diameter of the of the circular reducer and the speed of the air. The volumetric flow was set to $0.0931 \mathrm{~m}^{3} / \mathrm{s}$. The blower was turned off and the quinoa was poured into the reducer. The reducer was slid over the bottom of the air register assembly and the seam was sealed with duct tape. The 12"x12" HEPA air filter was fitted to the top of the plexiglass rectangle. The filter was lined up and clamped on all edges with spring clamps so that air could not escape through the sides. The blower was turned on and ran from 15 minutes. 
The blower was turned off and the HEPA filter was removed, weighed, photographed and recorded. Pressurized air was carefully used to move any dust and quinoa from the plexiglass rectangle, air register and any rough seams to the reducer. The reducer was removed, and the quinoa was poured over a mesh sieve of diameter 0.0559 inch and a catch basin. All of the quinoa and dust were shaken onto the sieve. The sieve and catch basin were shaken for 2 minutes and the amount collected at each level was measured, photographed and recorded. The flex ducting, reducer, and system base (air register and plexiglass rectangle) were weighed, photographed and recorded. A mass balance was calculated using the weights of quinoa and saponin containing fractions collected in the sieve and catch basin as well as the dust collected in the HEPA filter, flex ducting, reducer, and system base (air register and plexiglass rectangle). The test was performed in triplicate at 15 minutes with 800 grams.

\subsection{Tubular System}

The 5-gallon bucket was filled with water 2 inches above the opening of the inserted flexible tube. The initial weight of the polycarbonate tube disconnected from the air supply and 5-gallon bucket with the flexible tube attached were weighed, photographed and recorded before experimentation. 300 grams of Lundberg Family Farms Tri-Color Quinoa was weighed, photographed and recorded before experimentation

The rubber bung was pressed firmly into the bottom of the polycarbonate tube. The weighed quinoa was poured into the tube. The flexible tube was inserted into the top of the polycarbonate tube. The polycarbonate tube was placed into the cardboard rest and 
the angle was set to 32-degrees, measured and recorded. The air was turned on to 40 psi and the system was run for 15 minutes.

The air pressure was turned off as soon as the time had ended. A sieve of diameter 0.0559 inch and a catch basin were weighed and recorded. The flexible tube was removed from the top of the polycarbonate tube and set on top of the sieve. The flexible tube was shaken onto the sieve to remove any dust caught in between the 5-gallon bucket and the polycarbonate tube. The polycarbonate tube was removed from the cardboard rest and poured out onto the sieve. The bung was removed to ensure all grain was removed. The tube was flipped over and shook again to remove all dust. The polycarbonate tube was weighed and recorded to account for residual dust. The flexible tube was placed in the same position when previously weighed and the weight of the water was measured and

recorded. The sieve was shaken for 2 minutes and amount collected in the sieve and catch basin was measured, photographed and recorded. A mass balance was calculated using the weights of quinoa and saponin containing fractions collected in the sieve and catch basin as well as the dust collected in the polycarbonate tube and change in water weight. The test was performed in triplicate at 15 minutes with 300 grams at an angle of 32 degrees and a pressure of 40 psi.

\subsection{Evaluation of System Performance}

\subsection{Visual Observation}

Photos and videos were taken of the systems prior, during and after experimentation. The photos were used to analyze the amount of abrasive force acting upon the surface of the grain. The photos were also used to understand the flow of the grain in the system. 


\subsection{Mass Balance}

A mass balance was used to determine the amount of saponin containing fractions removed during processing. The following mass balance calculations were carried out: Input Grain Mass $=$ Processed Grain Mass + Sum of Saponin Containing Fractions

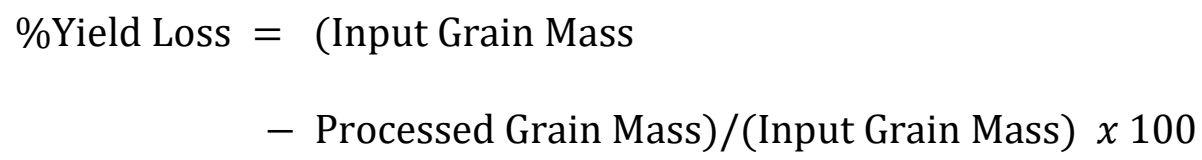

\subsubsection{Final Experiment with Tubular System}

The 5-gallon bucket was filled with water 2 inches above the opening of the inserted flexible tube. The initial weight of the polycarbonate tube disconnected from the air supply and 5-gallon bucket with the flexible tube attached were weighed, photographed and recorded before experimentation. Lundberg Family Farms Tri-Color Quinoa was weighed, photographed and recorded before experimentation. An experiential design was used to determine the process parameters for the system that resulted in the lowest saponin levels. A full factorial was designed with 3 levels of mass (200 grams, 300 grams, and 400 grams) and 3 levels of processing time (5 minutes, 10 minutes, and 15 minutes). The processing conditions for each sample as well as the order in which the samples were run. The randomized experimental design was developed and analyzed using the statistical software JMP to determine statistical interactions between process parameters (Table 3.1).

The rubber bung was pressed firmly into the bottom of the polycarbonate tube. The weighed quinoa was poured into the tube. The flexible tube was inserted into the top of the polycarbonate tube. The polycarbonate tube was placed into the cardboard rest and the angle was set to 32-degrees, measured and recorded. The air pressure was set to 40 
Table 3.5. Experimental Design for Tubular System.

\begin{tabular}{|c|c|c|c|c|}
\hline \multicolumn{2}{|c|}{ Experimental Run } & \multicolumn{2}{|c|}{ Independent Variables } & \multirow{2}{*}{$\begin{array}{l}\text { Response } \\
\text { Variable }\end{array}$} \\
\hline \# & ID & Time (min) & Mass (g) & \\
\hline 1 & 33 & 15 & 400 & \\
\hline 2 & 13 & 5 & 400 & \\
\hline 3 & 32 & 15 & 300 & \\
\hline 4 & 23 & 10 & 400 & \\
\hline 5 & 21 & 10 & 200 & \\
\hline 6 & 22 & 10 & 300 & \\
\hline 7 & 11 & 5 & 200 & \\
\hline 8 & 23 & 10 & 400 & \\
\hline 9 & 32 & 15 & 300 & \\
\hline 10 & 12 & 5 & 300 & \\
\hline 11 & 23 & 10 & 400 & \\
\hline 12 & 32 & 15 & 300 & \\
\hline 13 & 12 & 5 & 300 & Percent \\
\hline 14 & 12 & 5 & 300 & saponin \\
\hline 15 & 13 & 5 & 400 & $(\mathrm{w} / \mathrm{w})$ \\
\hline 16 & 22 & 10 & 300 & \\
\hline 17 & 11 & 5 & 200 & \\
\hline 18 & 31 & 15 & 200 & \\
\hline 19 & 13 & 5 & 400 & \\
\hline 20 & 21 & 10 & 200 & \\
\hline 21 & 33 & 15 & 400 & \\
\hline 22 & 21 & 10 & 200 & \\
\hline 23 & 22 & 10 & 300 & \\
\hline 24 & 33 & 15 & 400 & \\
\hline 25 & 31 & 15 & 200 & \\
\hline 26 & 31 & 15 & 200 & \\
\hline 27 & 11 & 5 & 200 & \\
\hline
\end{tabular}


psi and the system was run for the desired time.

The air pressure was turned off as soon as the time had ended. A sieve of diameter 0.0559 inch and a catch basin were weighed and recorded. The flexible tube was removed from the top of the polycarbonate tube and set on top of the sieve. The flexible tube was shaken onto the sieve to remove any dust caught in between the 5-gallon bucket and the polycarbonate tube. The polycarbonate tube was removed from the cardboard rest and poured out onto the sieve. The bung was removed to ensure all grain was removed. The tube was flipped over and shook again to remove all dust. The polycarbonate tube was weighed and recorded to account for residual dust. The flexible tube was placed in the same position when previously weighed and the weight of the water was measured and recorded. The sieve was shaken for 2 minutes and amount collected in the sieve and catch basin was measured. A $25 \mathrm{~mL}$ test tube was used to store quinoa for testing. The sample was collected by filling the tube half way by passing through the batch in a diagonal line. The remainder of the tube was filled by passing across the bottom of the batch. The sample was stored in refrigerated conditions at $50{ }^{\circ} \mathrm{F}$ until the sample was tested for saponin levels using the method listed in section 3.3.1.2. Complete Saponin Quantification Method. The method was repeated for each additional batch. A mass balance was calculated using the weights of quinoa and saponin containing fractions collected in the sieve and catch basin as well as the dust collected in the polycarbonate tube and change in water weight.

When testing the control, ten $\mathrm{mL}$ of grain was sampled from each bag at the top, middle, and bottom $(9,10 \mathrm{ml}$ samples) and combined in a coffee grinder. Five grams of 
the sample from the grinder were used for each replicate in the saponin quantification process. This procedure was repeated 6 times for the control sample.

The performance of the system was evaluated by comparing the saponin content of commercially processed washed quinoa with the quinoa processed by this method. The method was also compared to the saponin content of quinoa sourced from a quinoa processor at the three different stages of processing, raw grain, scarified grain, and scarified and washed.

\subsubsection{Saponin Quantification Method}

\subsubsection{Adaptations to the Saponin Quantification Method}

The methodology described by Ilce G. Medina-Meza, Nicole A. Aluwi, Steven R. Saunders, and Girish M. Ganjyal (2016) for the isolation and quantification of saponin in quinoa did not provide specific details of the different steps in the methodology. The different steps were defined through experimentation and are listed in Table 3.2. These adaptations are included in our method for saponin quantification.

Soxtec boiling, rinsing and evaporation times were based upon Soxtec standard operating procedures for fat extraction. Methanol/water $(4: 1)(35 \mathrm{~mL})$ was used as it was able to completely submerge the sample during boiling and still provide sufficient solution after extraction. Evaporation at a lower pressure and higher temperature was conducted due to the availability of equipment. The volume was reduced from a starting range of $16-20 \mathrm{~mL}$ to $10 \mathrm{~mL}$ during evaporation. Hydrolysis was first performed in a beaker, but the solution evaporated in minutes, so a reflux condenser was used to prevent evaporation and allow for 2 hours of hydrolysis. HCL $(5 \mathrm{~mL})$ was used to provide sufficient acid for the hydrolysis of the sample. This was confirmed with a consistent $\mathrm{pH}$ 
of 0 after hydrolysis. The sample was neutralized with $4 \mathrm{~N} \mathrm{NH}_{4} \mathrm{OH}$. During liquid-liquid partitioning the bottom layer was collected and tested for saponin. This yielded no reaction or color change. The top layer was then tested and confirmed to contain the saponin from the sample. The concentration of sulfuric acid was not listed, which led to problems in oxidizing the triterpenoid. Sulfuric acid $(36 \mathrm{~N})$ was found to adequately work and was used for the remainder of the experiment.

\subsubsection{Saponin Quantification using the Adapted Method}

Saponin content of unprocessed quinoa (control) and processed quinoa were determined using the adapted method. Quinoa samples (30g) were ground to a fine powder. The powder was defatted according to method ASCI 30-25.01. Defatted quinoa was extracted using the Soxtec method. The sample was boiled for 20 minutes, rinsed for 40 minutes in methanol/water solution $(35 \mathrm{~mL})(4: 1)$. The crude extract was concentrated at $2 \mathrm{mbar}$ and $35^{\circ} \mathrm{C}$ till the volume was reduced in half. The volume recovered after evaporation was recorded. Concentrate $(5 \mathrm{~mL})$ was hydrolyzed under reflux with $6 \mathrm{~N}$ $\mathrm{HCL}$ at $110^{\circ} \mathrm{C}$ for $2 \mathrm{~h}$ (Figure 3.7A). The hydrolysate was cooled, neutralized with $4 \mathrm{~N}$ $\mathrm{NH} 4 \mathrm{OH}$ and then centrifuged at $3000 \mathrm{~g}$ for 5 minutes. Saponins were isolated by a liquidliquid partition of ethyl acetate (Figure 3.7B). The solution was isolated 3 times using 5 $\mathrm{mL}$ of petroleum ether. The top layer was removed, and the bottom layer was repeated (Figure 3.7B). The top layers were combined and filtered in Na2SO4. Saponin extract $(500 \mu \mathrm{L})$ was mixed with glacial acetic acid/sulfuric acid $(1: 1 \mathrm{v} / \mathrm{v})(2000 \mu \mathrm{L})$. The mixture was vortexed for $30 \mathrm{~s}$ and then heated at $60{ }^{\circ} \mathrm{C}$ for 30 minutes. The mixture was then cooled in ice water for 3 minutes and measured in a spectrophotometer at $527 \mathrm{~nm}$. Glacial acetic acid was used as a blank and a standard curve was established using the 
Table 3.6. Adaptations to the Method of Saponin Quantification.

\begin{tabular}{|c|c|}
\hline Method & Adaptations/Changes \\
\hline Grinding of quinoa & $\begin{array}{l}\text { 1. Quinoa was ground in a coffee grinder till a fine } \\
\text { powder was produced. }\end{array}$ \\
\hline \multirow{3}{*}{ Fat extraction } & $\begin{array}{l}\text { 1. Soxtec Method with petroleum ether was used } \\
\text { instead of the traditional Soxhlet method to reduce } \\
\text { extraction time. }\end{array}$ \\
\hline & $\begin{array}{l}\text { 2. Sample was boiled for } 20 \text { minutes, rinsed for } 40 \\
\text { minutes and evaporated for } 10 \text { minutes with } 50 \mathrm{~mL} \\
\text { of petroleum ether. }\end{array}$ \\
\hline & $\begin{array}{l}\text { 3. A soxhlet reflux extractor was replaced with a Soxtec } \\
\text { machine to reduce sample time. }\end{array}$ \\
\hline Saponin extraction & $\begin{array}{l}\text { 1. } 35 \mathrm{~mL} \text { of methanol/water }(4: 1) \text { was boiled for } 20 \\
\text { minutes and rinsed for } 40 \text { minutes. }\end{array}$ \\
\hline \multirow{3}{*}{$\begin{array}{l}\text { Reduction of sample } \\
\text { volume }\end{array}$} & $\begin{array}{l}\text { 1. Evaporation was carried out in a centrifuge at } 0.1 \\
\mathrm{kPa} \text { at } 35^{\circ} \mathrm{C} \text {. }\end{array}$ \\
\hline & $\begin{array}{l}\text { 2. Volume from Soxtec extraction was reduced in half } \\
\text { during evaporation. }\end{array}$ \\
\hline & $\begin{array}{l}\text { 3. Total volume of solution after evaporation was } \\
\text { recorded. }\end{array}$ \\
\hline \multirow{2}{*}{ Hydrolysis } & $\begin{array}{l}\text { 1. } 5 \mathrm{~mL} \text { of solution was added with } 5 \mathrm{~mL} \text { of } 6 \mathrm{~N} \mathrm{HCl} \\
\text { and boiled under reflux for } 2 \mathrm{hrs} \text {. }\end{array}$ \\
\hline & $\begin{array}{l}\text { 2. The hydrolysate was cooled and neutralized with } 4 \mathrm{~N} \\
\mathrm{NH} 4 \mathrm{OH} \text {. }\end{array}$ \\
\hline Liquid-liquid portioning & $\begin{array}{l}\text { 1. During liquid-liquid portioning the top layer was } \\
\text { recovered } 3 \text { times and used for saponin } \\
\text { determination. }\end{array}$ \\
\hline $\begin{array}{l}\text { Sample preparation for } \\
\text { spectrophotometry }\end{array}$ & $\begin{array}{l}\text { 1. } 36 \mathrm{~N} \mathrm{H} 2 \mathrm{SO} 4 \text { was combined with glacial acetic acid } \\
\text { for the oxidation and reaction of the triterpenoid. }\end{array}$ \\
\hline
\end{tabular}


following concentrations of oleanolic acid in duplicate: $35.71 \mu \mathrm{g} / \mathrm{mL}, 50 \mu \mathrm{g} / \mathrm{mL}, 71.43$ $\mu \mathrm{g} / \mathrm{mL}, 100 \mu \mathrm{g} / \mathrm{mL}, 714.3 \mu \mathrm{g} / \mathrm{mL}$ and $1000 \mu \mathrm{g} / \mathrm{mL}$ (Medina-Meza et al., 2016). $50 \mu \mathrm{g} / \mathrm{mL}$ and $1000 \mu \mathrm{g} / \mathrm{mL}$ were performed in triplicate. A linear regression was plotted and the equation for the best fit was used to calculate the concentration of oleanolic acid equivalent in the solution. The concentrations were then used to determine the final amounts of saponin in the original batch. The total volume of the sample after filtration was measured to determine the dilution factor of the original sample tested. The volume was then multiplied by the concentration calculated by the standard curve and then multiplied by 5 , the final dilution of the original sample in the cuvette. This value was then divided by the weight of sample that was used at the beginning of the process multiplied by the percent of the sample used $(5 \mathrm{ml})$ after evaporation compared to the total volume after evaporation (\%Boiled). This was then multiplied by 100 to equal the percent of saponin in the sample.

Amount of Saponin in Sample

$=$ Total volume of Sample $(\mathrm{ml}) *$ Concentration $(\mathrm{g} / \mathrm{ml}) * 5$

Amount of Saponin in $1 \mathrm{~g}=\frac{\text { Amount of Saponin in Sample }}{\text { ground sample weight }(\mathrm{g}) * \% \text { Boiled }}$

Amount of Saponin in $1 \mathrm{~g} * 100=\%$ Saponin in Sample

\subsubsection{Data Analysis}

The final experiment with the tubular system was analyzed using a two-way ANOVA with Tukey's HSD to determine statistical differences. One-way ANOVA with Tukey's HSD were used in testing the difference in commercially processed samples and difference in tube surface. Means comparison with Dunnett's Method was used to determine if the processing conditions from the DOE were different from the control. All statistical analysis was conducted in the statistical software JMP. 

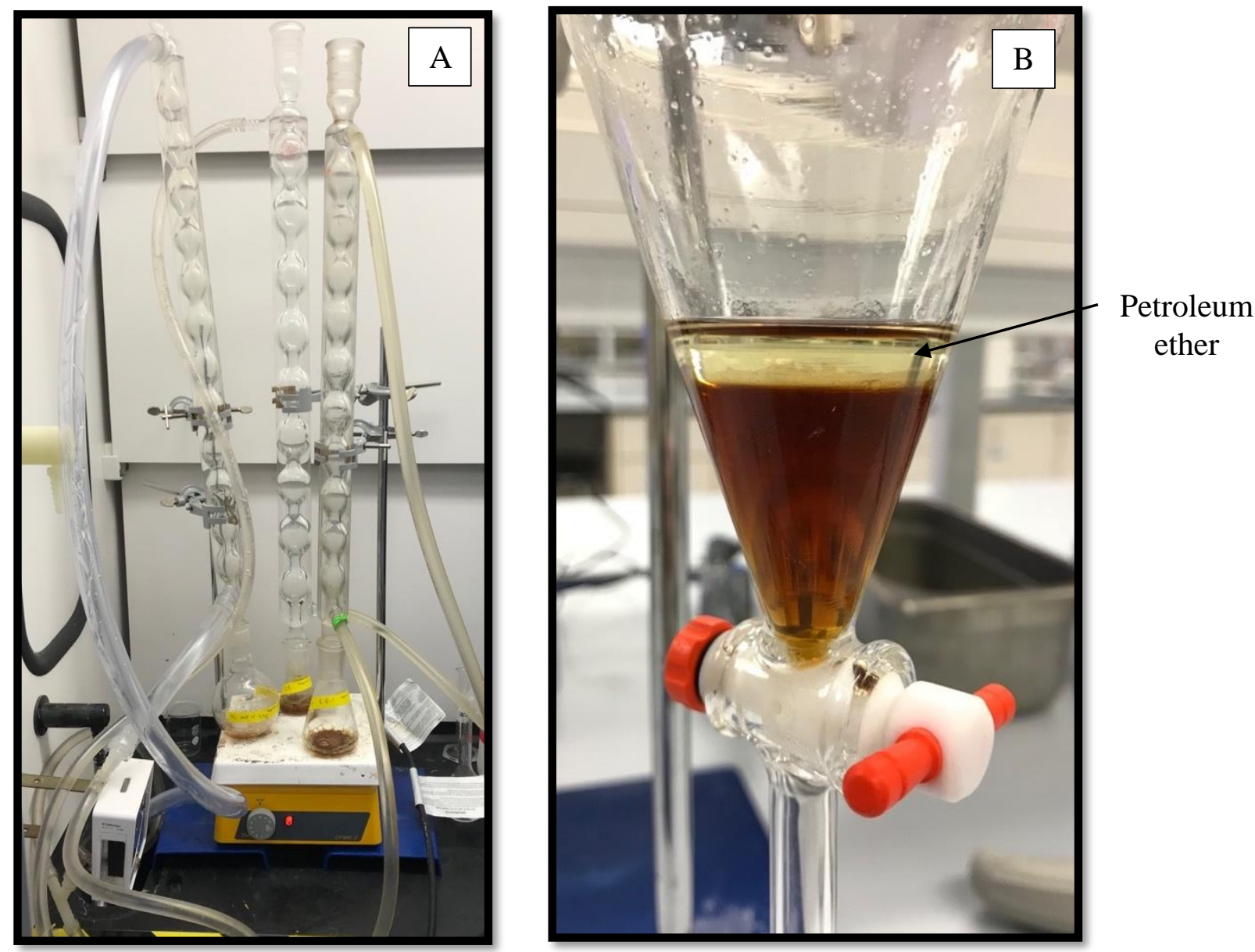

Figure 3.7. Methods Used for the Quantification of Saponin in Quinoa. A: Hydrolysis under reflux, B: Liquid-liquid partitioning. 


\section{RESULTS AND DISCUSSION}

\subsection{Preliminary Experiments}

All preliminary experiments were evaluated by visual observation of saponin removal and mass balance. Quinoa processed using three systems were compared to scarified and scarified-washed commercial products.

\subsubsection{Conical System}

The conical system was used in this study to replicate the work of researchers at the Universidad Privada Boliviana in developing a complete system for the removal of saponin from quinoa. The system was operated for 15 minutes. The pressure remained constant at 11 psi through a 0.25 -inch fitting as well as the input mass of 300 grams quinoa. After 15 minute process time the saponin removal was not uniform. Some grains displayed partial removal while a majority of the grain appeared to not have received any abrasion (Figure 4.1A\&B).

The mass balance results showed the system was able to remove around $1.3 \%$ of the quinoa mass (Table 4.1.). The system had good vertical flow of air moving quinoa from the bottom of the tank to the top but had little horizontal movement (Figure 4.1C). The original system design idea was to incorporate some horizontal stirring and movement of the grain that would increase the vertical flow distribution of grain as well as increase grain-to-grain abrasion. The main region of abrasion was located in the neck of the conical tank. This area accounted for a small proportion of the overall volume of the grain in the tank. At this pressure the grain was pushed almost to the top of the tank and then fell back onto the surface of the grain. The movement of the grain was restricted to the center of the tank. This phenomenon reduced the 
Table 4.1. Conical System Mass Balance Results.

\begin{tabular}{|c|c|c|c|c|c|c|c|c|c|}
\hline \multirow{2}{*}{ Run } & \multirow{2}{*}{$\begin{array}{l}\text { Time } \\
(\min )\end{array}$} & \multicolumn{2}{|c|}{$\begin{array}{c}\text { Sample } \\
\text { Weight }(\mathrm{g})\end{array}$} & \multicolumn{2}{|c|}{$\begin{array}{l}\text { Tank Base } \\
\text { Weight (g) }\end{array}$} & \multicolumn{2}{|c|}{$\begin{array}{l}\text { Filter Weight } \\
(\mathrm{g})\end{array}$} & \multirow{2}{*}{ 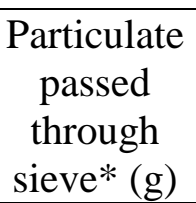 } & \multirow{2}{*}{$\begin{array}{l}\text { Yield } \\
\text { Loss } \\
(\%)\end{array}$} \\
\hline & & Start & Finish & Start & Finish & Start & Finish & & \\
\hline 1 & 15 & 300 & 296 & 558 & 558 & 415 & 417 & 2 & 1.3 \\
\hline 2 & 15 & 300 & 297 & 558 & 558 & 416 & 417 & 1 & 1.0 \\
\hline 3 & 15 & 300 & 296 & 558 & 558 & 415 & 416 & 2 & 1.3 \\
\hline
\end{tabular}

*Sieve opening diameter 0.0559 inch 

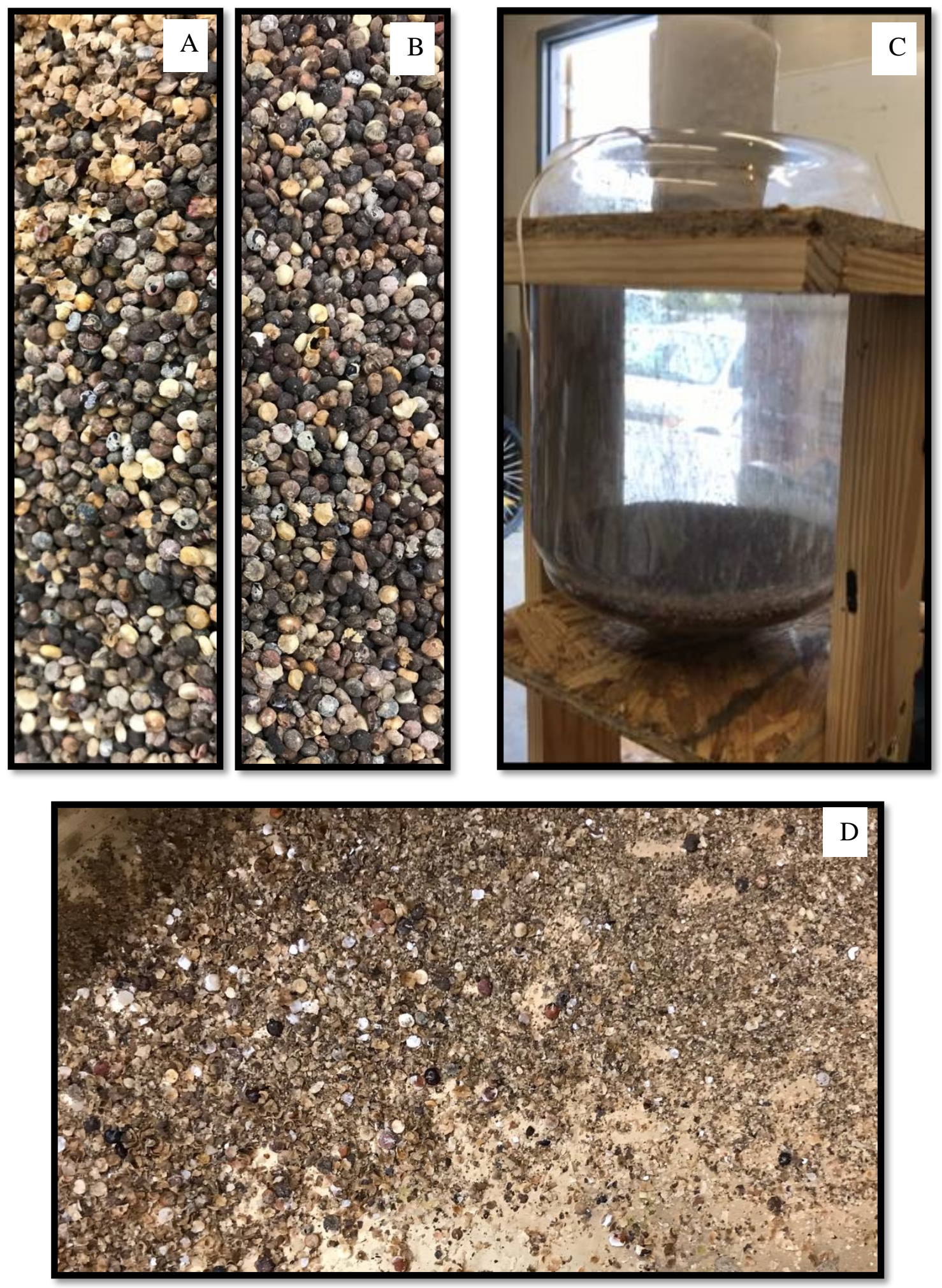

Figure 4.1. Processing Quinoa in a Conical Tank System. A: Quinoa after processing for 15 mins. B: Control quinoa. C: Conical tank during processing. D: Substance removed during processing $\leq 0.0559$-inch diameter. 
movement of the grain on the top outer ring of the tank and thus reduced grain-to-surface and grain-to-grain interactions. The grain did eventually reach all areas of the tank, but not in a consistent uniform order. This resulted in some grain receiving more abrasive interactions and saponin removal than other grains receiving very little, if any, saponin removal (Figure 4.1C). The area that appeared to have the greatest impact on saponin removal was the neck of the tank. This area produced a strong "churning" affect that forced the grains to push against each other.

The filter attached at the top tank surface became very thick with a layer of brown dust after processing. The change in weight of the filter was often between 1.0-2.0 grams with higher filter weights associated with greater quinoa mass removal.

It was also noted that the distance the grain traveled through quinoa mass was very short. The angled conical slope of the tank was much less mild than desired. This reduced grain interactions that could have occurred if the distance the grain travelled against grain was increased. Greater mass inputss of grain were attempted, but the air volume capabilities of the system were not great enough to facilitate grain movement in the tank. The intensity of which the grain was forced to interact with other grains was very mild.

This preliminary study emphasized the need of a system that allowed uniform grain movement to promote grain-to-grain interactions. In addition, increasing surface-tograin abrasion will improve saponin removal while reducing process time. The churning effect produced in the neck of the tank was noted and applied to the tubular model. 


\subsubsection{Fluidized Bed}

The fluidized bed system was an attempt to address the shortcomings of the conical tank system. Visual observation indicated very little removal of surface coating (Figure 4.2A-C). Some of the grains had surface removal, but the removal was not consistent among all of the grains. The mass balance results showed less than $0.6 \%$ removal of quinoa grain mass (Table. 4.2). The filter accumulated a layer of brown dust after processing (Figure 4.2D). The change in weight of the filter was between 2-3 grams.

The system had good vertical flow of air moving quinoa from the bottom of the system to the top. The system was designed after the principals of a fluidized bed that would keep the grains in a fluidized state, consistently rubbing against each other to achieve grain-to-grain abrasion. However, the intensity of the system was again mild and did not force strong interactions of the grain (Figure 4.2E). The interactions of the quinoa with the surface of the system did not have a visible effect on the removal of the saponin. The flow of the air blower was also irregular when the quinoa was added to the system. A small amount of quinoa was always in continuous movement while the majority of the grain was moving up and down together. The quinoa would accumulate and block the air flow until enough was lifted off and the rest of the grain would shoot up and repeat this movement throughout the run.

\subsubsection{Tubular System}

Visual removal of surface coating was apparent on most grains (Figure 4.3A\&B). The mass balance results revealed that between $4.0-4.66 \%$ of the quinoa mass was being removed (Table 4.3). The mass balance design for the system was unable to gather an accurate account of the change in mass during processing. The saponin containing 
Table 4.2. Mass Balance Results from Fluidized Bed.

\begin{tabular}{|c|c|c|c|c|c|c|c|c|c|c|c|}
\hline \multirow[t]{2}{*}{ Run } & \multirow[t]{2}{*}{$\begin{array}{l}\text { Time } \\
(\min )\end{array}$} & \multicolumn{2}{|c|}{$\begin{array}{c}\text { Sample Weight } \\
(\mathrm{g})\end{array}$} & \multicolumn{2}{|c|}{$\begin{array}{c}\text { Flex Ducting } \\
\text { and System } \\
\text { Base Weight } \\
(\mathrm{kg})\end{array}$} & \multicolumn{2}{|c|}{$\begin{array}{c}\text { Funnel Weight } \\
(\mathrm{kg})\end{array}$} & \multicolumn{2}{|c|}{$\begin{array}{l}\text { Filter Weight } \\
(\mathrm{g})\end{array}$} & \multirow{2}{*}{$\begin{array}{l}\text { Particulate } \\
\text { passed } \\
\text { through } \\
\text { sieve* }(\mathrm{g})\end{array}$} & \multirow[t]{2}{*}{$\begin{array}{l}\text { Yield } \\
\text { Loss } \\
(\%)\end{array}$} \\
\hline & & Start & Finish & Start & Finish & Start & Finish & Start & Finish & & \\
\hline 1 & 15 & 800 & 796 & 3.7 & 3.7 & 0.2 & 0.2 & 74 & 76 & 2 & 0.50 \\
\hline 2 & 15 & 800 & 795 & 3.7 & 3.7 & 0.2 & 0.2 & 74 & 77 & 2 & 0.62 \\
\hline 3 & 15 & 800 & 796 & 3.7 & 3.7 & 0.2 & 0.2 & 74 & 76 & 2 & 0.50 \\
\hline
\end{tabular}

*Sieve opening diameter 0.0559 inch 

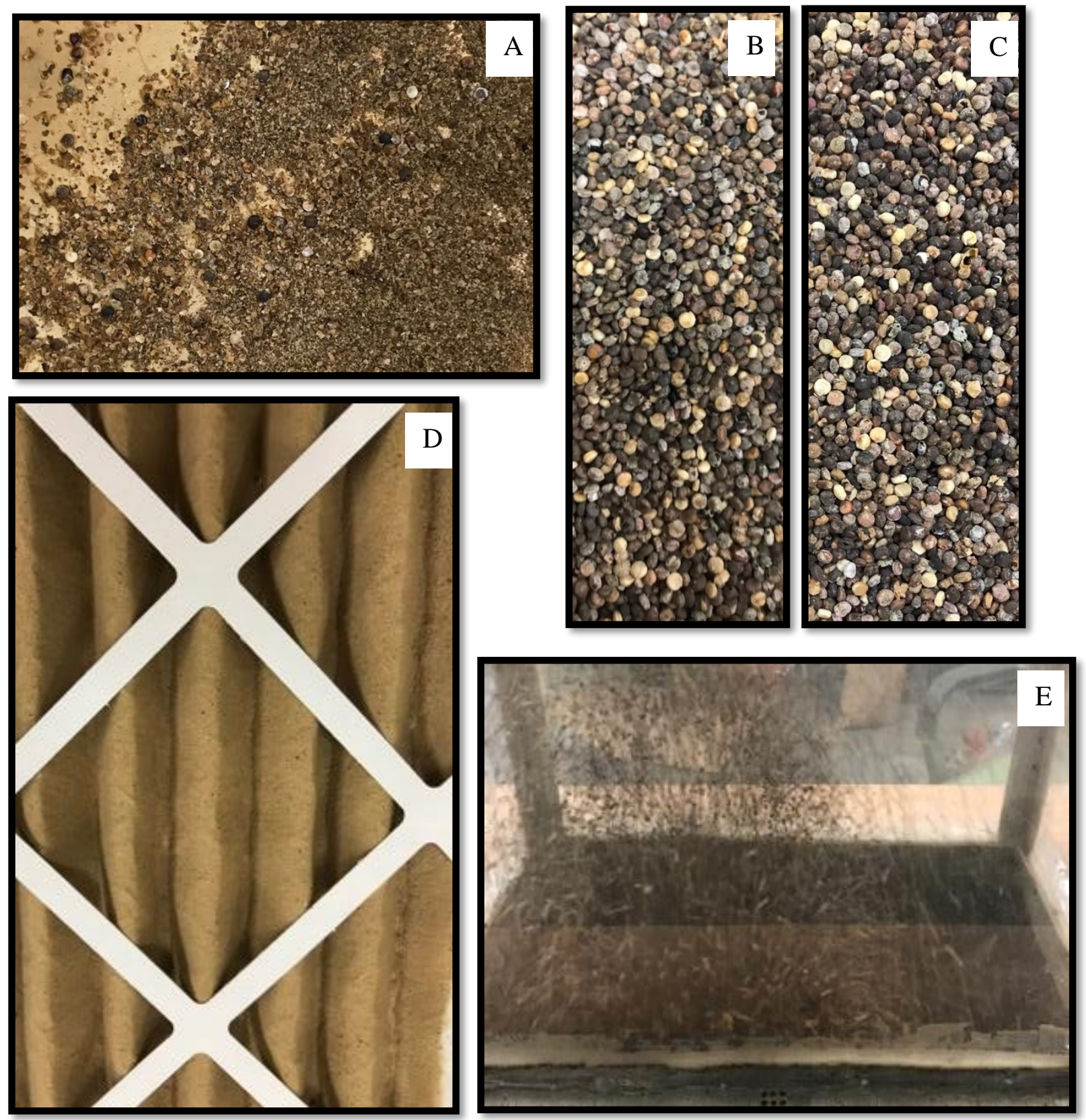

Figure 4.2. Processing Quinoa in a Fluidized Bed System. A: Substance removed during processing < 0.0559-inch diameter. B: Quinoa after processing 15 minutes C: Control quinoa. D: Filter after 15 minutes of processing. E: Fluidized bed system during processing. 

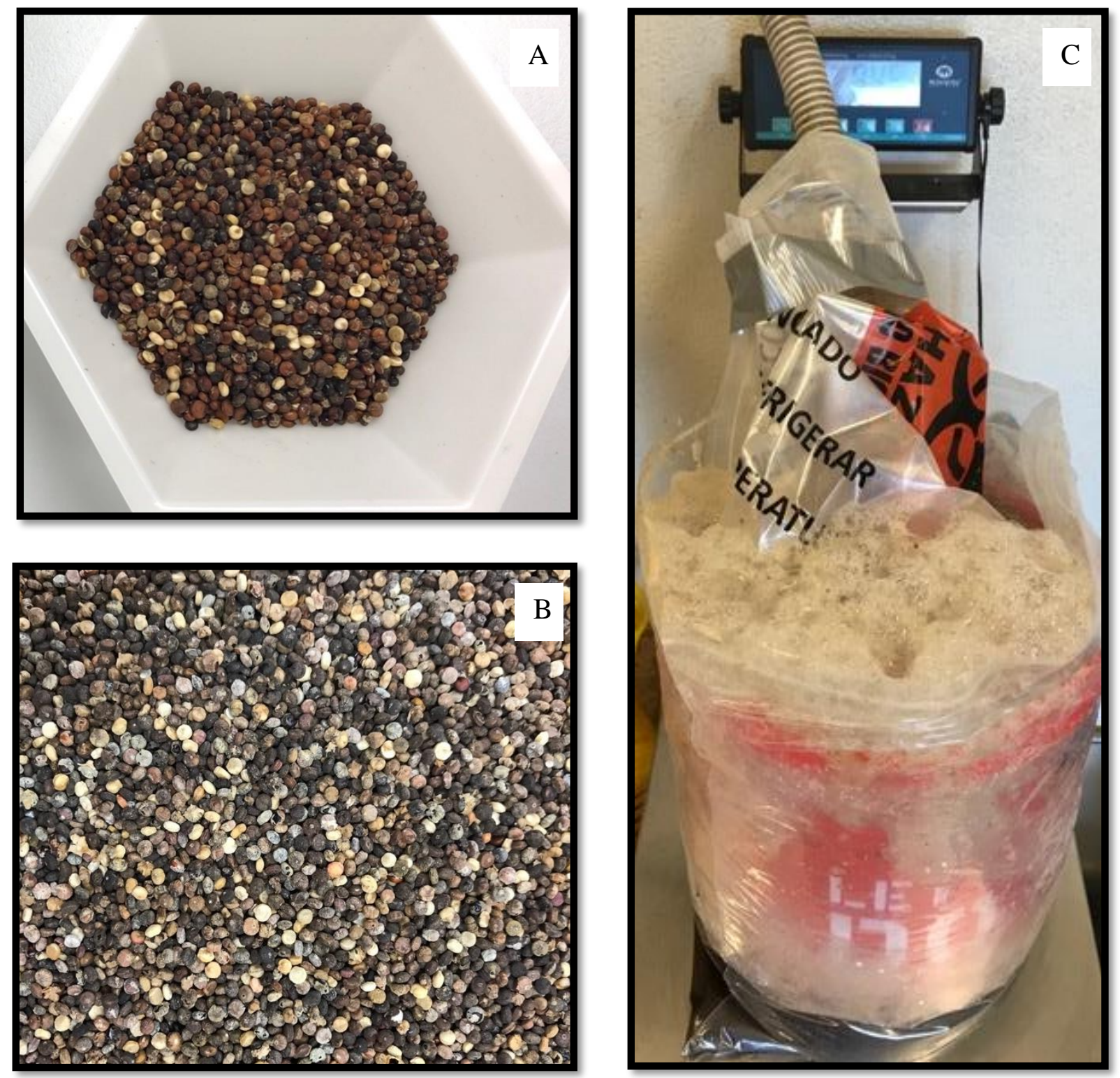

Figure 4.3. Processing Quinoa in Tubular System. A: Quinoa after processing 15 minutes B: Control quinoa. C: Saponin and water foaming during processing. 
Table 4.3. Tubular System Mass Balance Results.

\begin{tabular}{|c|c|c|c|c|c|c|c|c|c|}
\hline \multirow{2}{*}{ Run } & \multirow{2}{*}{$\begin{array}{l}\text { Time } \\
(\min )\end{array}$} & \multicolumn{2}{|c|}{$\begin{array}{c}\text { Sample } \\
\text { Weight (g) }\end{array}$} & \multicolumn{2}{|c|}{$\begin{array}{l}\text { Tank Base } \\
\text { Weight }(\mathrm{g})\end{array}$} & \multicolumn{2}{|c|}{$\begin{array}{c}\text { Water } \\
\text { Weight }(\mathrm{kg})\end{array}$} & \multirow{2}{*}{ 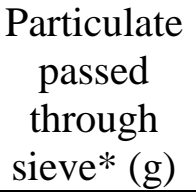 } & \multirow{2}{*}{$\begin{array}{c}\text { Yield } \\
\text { Loss }(\%)\end{array}$} \\
\hline & & Start & Finish & Start & Finish & Start & Finish & & \\
\hline 1 & 15 & 300 & 288 & 468 & 469 & 6.57 & 6.58 & 6 & 4.00 \\
\hline 2 & 15 & 300 & 286 & 468 & 469 & 6.58 & 6.59 & 7 & 4.67 \\
\hline 3 & 15 & 300 & 286 & 468 & 469 & 7.76 & 7.75 & 7 & 4.67 \\
\hline
\end{tabular}

*Sieve opening diameter 0.0559 inch 
fractions and dust were removed from the system by the compressed air. A water filter, used to collect the dust and allow the air to escape without changing the flow of air within the tubular system, performed poorly. The saponin in the dust produced a strong foam when combined with water. This foam was mostly contained within the designated space of the bucket but would occasionally overflow during the processing runs that removed the most saponin (Figure 4.3C). The overflowing of foam outside of the bucket prevented the collection of accurate mass balance weights.

The tubular system achieved the highest removal of grain surface coating and was selected for further experimentation. The tubular system used as the final design to determine the effect of additional friction on reducing the overall processing time of an abrasion only system.

\subsection{Saponin Estimation}

\subsubsection{Final Adapted Method for Saponin Quantification}

The results from the saponin quantification method for unscarified quinoa were similar to the range of the values reported by Ilce G. Medina-Meza, Nicole A. Aluwi, Steven R. Saunders, and Girish M. Ganjyal (2016) (Table 4.4).

Table 4.4 Saponin Content of Unscarified Quinoa Confirming the Validity of the Adapted Method.

\begin{tabular}{lll}
\hline Method & Data Obtained at & $\begin{array}{l}\text { Saponin Range }(\mathrm{g} / 100 \mathrm{~g} \\
\mathrm{DW})\end{array}$ \\
\hline & $\begin{array}{l}\text { School of Food Science, } \\
\text { Washington State University, }\end{array}$ & $0.66-3.09$ \\
UV-Vis & $\begin{array}{l}\text { Pullman Washington, United } \\
\text { States, 2016 }\end{array}$ & \\
& $\begin{array}{l}\text { Department of Food Science, } \\
\text { California Polytechnic State } \\
\text { University San Luis Obispo, 2019 } \\
\text { Study }\end{array}$ & $0.53-2.06$ \\
\hline Spectrophotometry & \\
\hline
\end{tabular}


The standard curve of oleanolic acid used to determine the amount of saponin in the different samples is shown in Figure 4.4.

\subsection{Final Experiment with Tubular System}

The mean saponin content at different process parameters and control are represented in Figure 4.5. The processing conditions of 15 minutes at an input mass of 300 grams yielded the lowest saponin content, $0.19 \%$ (Figure 4.5 ). The four processing conditions of (10 minutes/200 grams, 10 minutes/400 grams, 15 minutes/200 grams and 15 minutes/300 grams) were statistically different from the control (unprocessed quinoa) (Figure 4.5). The ANOVA results for the experimental design are shown in Table 4.5. The effects of process time, input mass, and the interaction between process time and input mass were not statistically significant (Table 4.5).

The saponin content of quinoa processed using smooth and rough tubular systems is shown in Figure 4.6. The processing of the grain in smooth and rough tubular systems did not show any statistical difference. However, the treatment of 15 minutes and 300 grams input mass in the rough tube had the lowest saponin content $(0.19 \%)$ compared to all other process parameters in the smooth tube (Figure 4.6).

The tubular system was able to incorporate grain-to-surface friction and highintensity grain-to-grain abrasion through a "churning" motion. Grain-to-surface interactions occurred as the grain was pushed to the top of the tube and fell back to the bottom, rubbing against the tube surface during each cycle. High-intensity grain-to-grain abrasion was observed when the grain was pushed to the top of the tank by the compressed air. However, the intensity of the abrasion was low during the return flow of 




Figure 4.4. Linear Regression of the Standard Curve of Oleanolic Acid at $527 \mathbf{~ n m}$. 


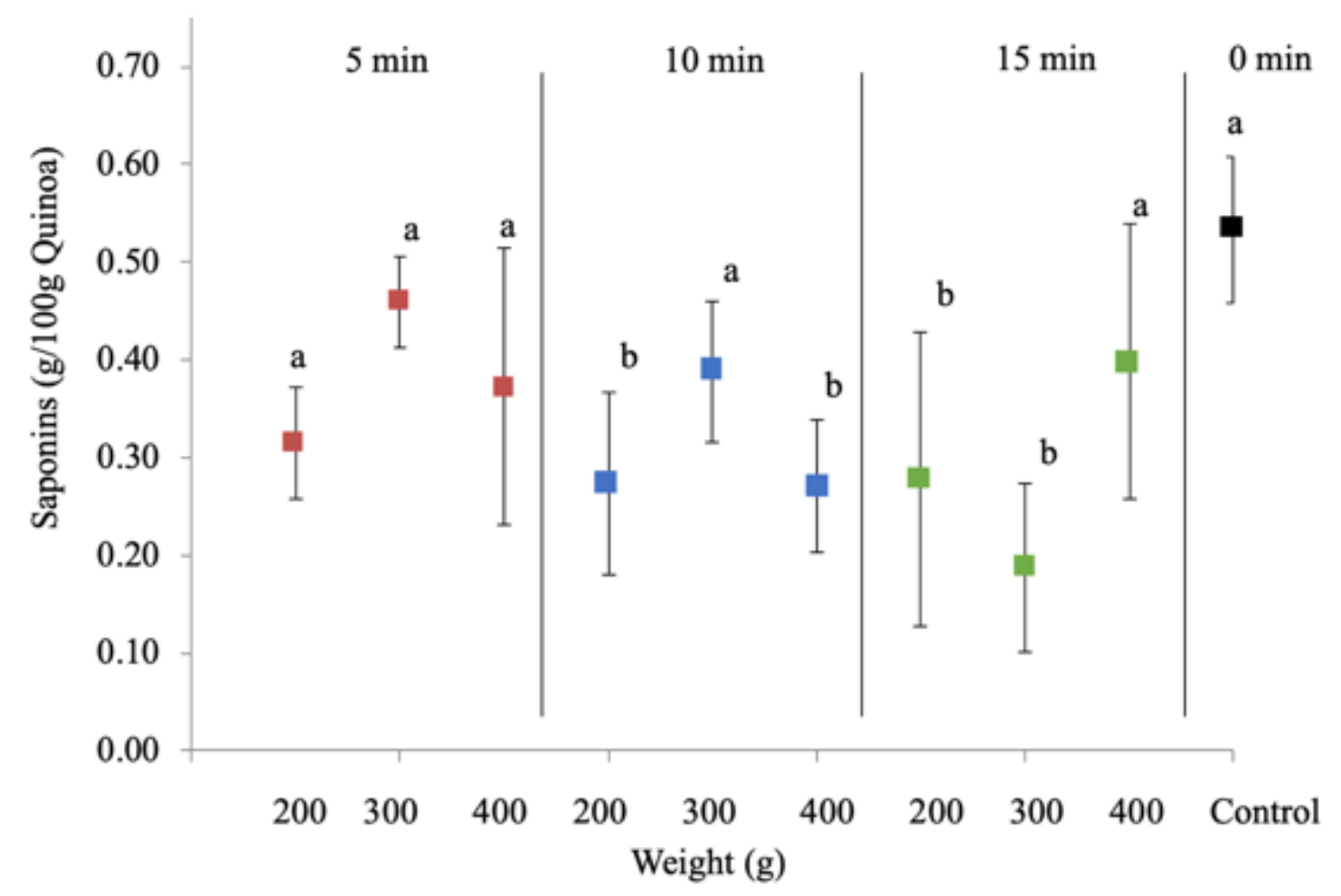

Figure 4.5. Percent Saponin in Samples After Processing at Different Time and Mass

Combinations. Data points represent a mean $(n=3)$. Errors bars denote standard deviations. Bars showing a different letter than the control are statistically different $(\mathrm{p} \leq 0.05)$. 
Table 4.5.ANOVA Results from DOE of Processing Conditions.

\begin{tabular}{cccccc}
\hline Source & $\begin{array}{c}\text { Total Sum of } \\
\text { Squares }\end{array}$ & DF & $\begin{array}{c}\text { Mean Sum } \\
\text { of Squares }\end{array}$ & F-Ratio & P Value \\
\hline Time & 0.04408 & 2 & 0.02204 & 2.1143 & 0.1497 \\
Weight & 0.01970 & 2 & 0.00985 & 0.9452 & 0.4071 \\
Time*Weight & 0.10647 & 4 & 0.0266175 & 2.5536 & 0.0745 \\
Error & 0.18763 & 18 & 0.01042389 & - & - \\
\hline
\end{tabular}




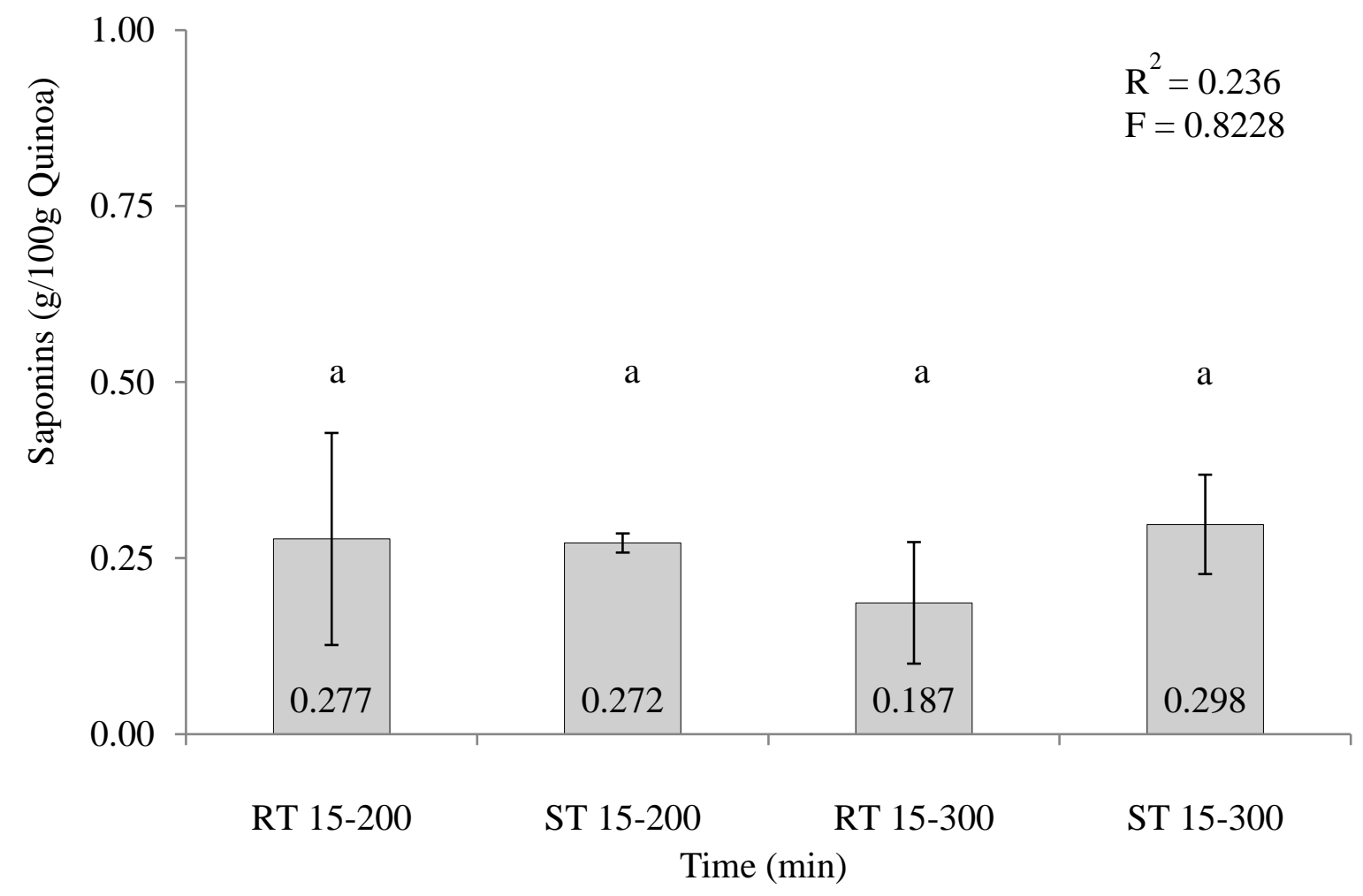

Figure 4.6. Percent Saponin in Samples After Processing With Different Surface Roughness and Different Input Mass. Data points represent a mean $(n=3)$. The numbers within the bar show the mean saponin content after processing. Errors bars denote standard deviations. Bars showing the same letters are not statistically different $(\mathrm{p} \leq 0.05)$. 
the grain to the bottom of the tube, as shown in Figure 3.5. The angle of the tube facilitated a slow sliding of the grain down the tube.

\subsubsection{Effectiveness of the System}

The saponin content of commercially processed grain is shown in Figure 4.7. Washing of the scarified quinoa (both white and tri-color) reduced the saponin levels further but was not statistically different compared to scarification.

The saponin levels of four different commercially available bagged quinoa (washed or scarified and washed) are shown in Figure 4.8. The high variability in the tricolor (D) and tubular system processed quinoa (15 minutes and 300 grams) could be linked to the nature of the blend as a combination of three varieties with different composition and levels of saponin and could respond differently to abrasion and washing as reported by Ridout et al. (1991). Differences between the washed quinoa samples were observed but were not statistically significant. The tubular system reduced the saponin level to $0.19 \%$ compared to the best commercially available sample with saponin content of $0.21 \%$. The results show the potential of improving saponin removal using the tubular system. However, further research will be needed.

Future research would focus on the increase surface friction. Additional surface friction is likely to be a factor in reducing the overall process time. If the system were to be scaled, the effect of tube diameter would need to be determined. Changes to the diameter of the tube would have direct changes in the surface area of the grain and intensity of the grain-to-grain interactions. Alternative source of air needs to be investigated. This has the potential to reduce the cost of operation and change grain-tograin interactions. 







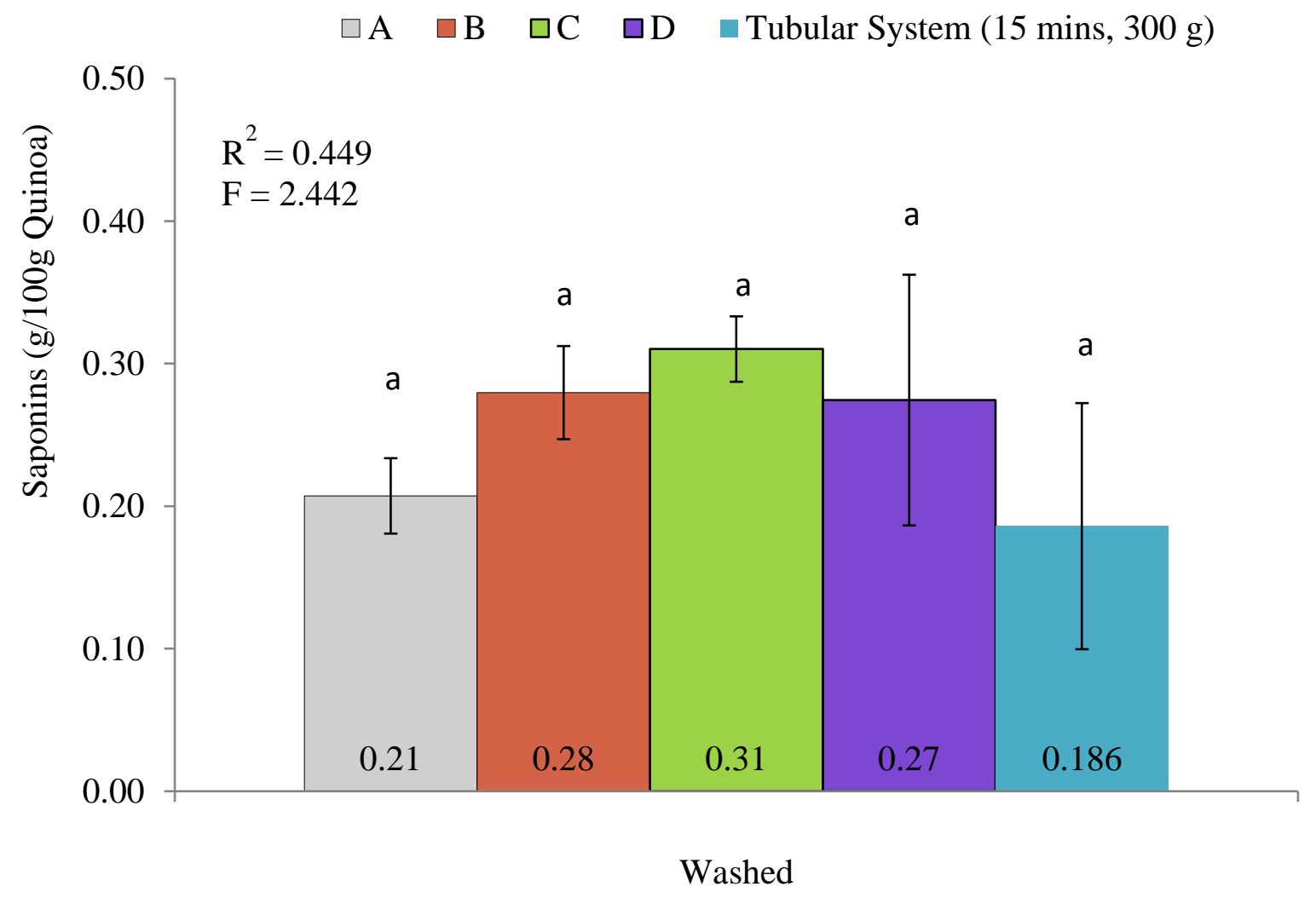

Figure 4.8. Difference in Saponin Levels Between Washed and Scarified White Quinoa (A), White Quinoa (B), Washed Tri-Color Quinoa (C), and Washed Tri-Color

Quinoa (D). Washed tri color quinoa (C) had the highest levels of saponin at 0.31 $\mathrm{g} / 100 \mathrm{~g}$. Washed white quinoa (A) had the lowest levels of saponin at $0.21 \mathrm{~g} / 100 \mathrm{~g}$. The tubular system (15 mins, $300 \mathrm{~g}$ ) had the lowest mean value. The numbers within the bar show the mean saponin content after processing. Errors bars denote standard deviations. Bars showing the same letter are not statistically different $(p \leq 0.05$, 


\section{SUMMARY AND CONCLUSIONS}

Three abrasion systems were designed, fabricated and tested to determine the effects of abrasion alone on the removal of saponin from quinoa. Preliminary testing using mass balance and visual observation indicated the potential of the tubular system to create the most abrasive forces of the three systems. Further experimentation with the tubular system showed that the adjustment of process time and input grain mass can be used to maximize saponin removal. The creation of surface roughness to the tubular system appeared to have an impact on saponin removal and needs to be studied further. The processing time with the tubular system ranges from 10 to 15 minutes and can be reduced with further experimentation.

Industrial scale implementation of the system would improve saponin removal from quinoa. The system would provide the industry with a sustainable process with better saponin removal capacity.

Future focus should be on increasing surface friction, and the change in tube and air inlet diameter. Additional surface friction is likely to be a factor in reducing the overall process time. Changes to the diameter of the tube and air inlet would have direct changes in the surface area of the grain and intensity of the grain-to-grain interactions and needs to be further studied. 


\section{REFERENCES}

Ando, H., Chen, Y.-C., Tang, H., Shimizu, M., Watanabe, K. \& Mitsunaga, T. (2002). Food Components in Fractions of Quinoa Seed. Food Sci. Technol. Res, 8, 80-84.

Arendt, E.K. \& Zannini, E. (2013). Quinoa. In: Cereal Grains for the Food and Beverage Industries. Pp. 409-438.

Balize, D;Bertero, D; Nieto, C. (FAO \& C. (2015). State of the art report on quinoa around the world in 2013. Rome: FAO.

Escalera Vásquez, R., Ledezma, C.Q. \& Weill, L.A. (2010). DESARROLLO Y DESEMPEÑO DE UN PROCESO DE BENEFICIADO EN SECO DE VARIEDADES AMARGAS DE QUINUA BASADO EN LA APLICACIÓN DE UN LECHO FLUIDIZADO DE TIPO SURTIDOR (LFTS), 10, 5-22.

Gonzalez, J.A., Rolden, A., Gallardo, M., Escudero, T. \& Prado, F.E. (1989). Quantitative determinations of chemical compounds with nutritional value from inca crops:Chenopodium quinoa (?quinoa?). Plant Foods for Human Nutrition, 39, 331337.

Kozioł, M.J. (1992). Chemical composition and nutritional evaluation of quinoa (Chenopodium quinoa Willd.). Journal of Food Composition and Analysis, 5, 3568.

Medina-Meza, I.G., Aluwi, N.A., Saunders, S.R. \& Ganjyal, G.M. (2016). GC-MS Profiling of Triterpenoid Saponins from 28 Quinoa Varieties ( Chenopodium quinoa Willd.) Grown in Washington State. Journal of Agricultural and Food Chemistry, 64, 8583-8591.

Nickel, J., Spanier, L.P., Botelho, F.T., Gularte, M.A. \& Helbig, E. (2016). Effect of 
different types of processing on the total phenolic compound content, antioxidant capacity, and saponin content of Chenopodium quinoa Willd grains. Food Chemistry, 209, 139-143.

Ridout, C.L., Price, K.R., Dupont, M.S., Parker, M.L. \& Fenwick, G.R. (1991). Quinoa saponins - analysis and preliminary investigations into the effects of reduction by processing. Journal of the Science of Food and Agriculture, 54, 165-176.

Scanlin, L. \& Lewis, K.A. (2017). Chapter 14 - Quinoa as a Sustainable Protein Source: Production, Nutrition, and Processing BT - Sustainable Protein Sources. Pp. 223238. San Diego: Academic Press.

Simmonds, N.W. (1965). The grain chenopods of the tropical American highlands. Economic Botany, 19, 223-235. 